\title{
A 2D finite volume simulation tool to enable the assessment of combined hydrological and morphodynamical processes in mountain catchments th
}

\author{
J. Fernández-Pato ${ }^{1}$ \\ C/María de Luna 3, Edif. Torres Quevedo, 50018, Zaragoza (Spain) \\ S. Martínez-Aranda ${ }^{2}$ \\ C/María de Luna 3, Edif. Torres Quevedo, 50018, Zaragoza (Spain) \\ P. García-Navarro ${ }^{2}$ \\ C/María de Luna 3, Edif. Torres Quevedo, 50018, Zaragoza (Spain)
}

\begin{abstract}
Nowadays, the great power of modern computers allows to develop computational models able to deal with simulations of several coupled phenomena over detailed complex topography. An efficient and properly calibrated computational model represents a useful tool to provide insight into the catchment dynamics at hydrological and geomorphological levels. In addition, it allows to develop detailed risk management and conservation plans. In this work, we present a coupled surface-groundwater distributed flow model with hydrological (rainfall and infiltration) and geomorphological (suspended and bed load sediment transport) components. The coupled model is applied to well characterized experimental catchments that are used as realistic test cases. The calibration of the water flow model response to rainfall is performed by means of the fitting to experimental outlet hydrographs of the results supplied by a coupled formulation of 2D Shallow Water Equations and 2D Darcy's law for saturated porous media connected via suitable infiltration laws. The calibration
\end{abstract}

\footnotetext{
Special Issue on Shallow Flow Models for Advances in Water Resources.

${ }^{1}$ Fluid mechanics-University of Zaragoza, Hydronia-Europe S.L.

${ }^{2}$ LIFTEC(CSIC), Fluid mechanics-University of Zaragoza
} 
of a suspended and bed load model is also addressed by means of the fitting to experimental outlet sedigraphs. The numerical results show a good agreement between numerical and observed hydrographs and sedigraphs, significantly improving previous published simulations. Additionally, the need to repeat the simulations in the calibration processes is no longer an unapproachable problem. Keywords: Shallow flows, Groundwater flow, Sediment transport, Infiltration, Coupled models

2010 MSC: 00-01, 99-00

\section{Introduction}

Environmental-related sciences have evolved in the last decades due in part to the introduction of simulation techniques at catchment scale [1, 2, 3. Most of the processes participating in the hydrological cycle can be considered, in a

5 distributed way by discretizing the spatial domain in as many computational cells as necessary, conforming the discrete mesh. Each cell works as a water and sediment control volume where the net surface water flow and sediment transport inputs/outputs, the rainfall input, the infiltration/exfiltration fluxes and the changes in bed level due to erosion/deposition processes are taken into 10 account.

In the last decades, the increasing awareness of the relevance of catchmentscale hydrology and morphodynamics led to numerous authors to develop numerical models able to simulate different physical processes in mountain basins, such as distributed rainfall-runoff conversion [4, 5, 6, infiltration-exfiltration processes related to the groundwater flow [7, 8, 9, or sediment dynamics (erosiondeposition and morphodynamics changes in the watershed) [10, 11, 12]. Recent reviews of the state of the art of both branches are covered in [13] and [14]. However, it is not common to find models that couple surface and groundwater flows together with erosion-deposition processes that combine both suspended load and bed transport.

Numerical methods used as computational strategy of hydrological and sed- 
iment transport models usualy demand a large computational effort for their calculations [15]. When considering the simulation of natural catchments, the domains of interest are usually large and the most common situation to consider is the simulation of rainfall/runoff events, where the problem is controlled by the wet/dry front over irregular topography. All these factors contribute to increase the complexity of the numerical model.

In this article, data from two sub-Mediterranean experimental mountain catchments, Arnás and Araguás, are used. Both basins have been widely studied and characterized from an experimental point of view by researchers from the IPE/CSIC [16, 17]. The reason to choose these catchments is the availability of field data of different processes involved in a few past events. Several storm events have been measured and reported in the last decades and the hydraulic and geomorphological response of both catchments have been evaluated, generating observed hydrographs and sedigraphs which represent a proper way to calibrate our hydrodynamic and sediment transport numerical models in situations involving coupled processes. Additionally, some piezometric data of the phreatic level evolution are available at certain locations of the Arnás catchment [16. Both catchments have also been studied from a numerical perspective in 40 the past, focusing on the calibration of the infiltration component of the model [18, 19, 5, 6]. In [19] the influence of the computational mesh over the numerical runoff generation was studied, leading to an optimal choice which is the mesh used here.

In the context of this Special Issue, the present work is focused on the use of 45 a $2 \mathrm{D}$ shallow water flow model as the basis of a simulation tool that combines overland flow, infiltration, groundwater flow and sediment transport in a single coupled model. To the authors' knowledge this approach is not extended. The work is oriented to show that traditionally used simplified models, such as diffusive (zero-inertia) or kinematic wave models for the overland flow or hill-slope erosion models for the erosive part [12, 20, can be replaced by the shallow water equations based models. Also, the novelty of our approach is oriented to show the interest of combining robust and well balanced finite volume simulation 
schemes for both the hydrological flow and the sediment transport. Infiltration and sediment transport models require as input data a set of parameters dependent mainly on the soil and sediment properties. A proper calibration of these parameters is necessary to achieve an accurate result for the surface runoff and thus for the erosion/deposition processes.

The increase in the power of computers and the possibility of developing parallelized computer codes has led to a notable improvement in the efficiency of numerical simulations [21, 15, 22. This fact is of special relevance if a calibration process must be assessed, due to the number of simulations that have to be performed in order to fit the numerical results to the observed data [19, 5].

In the approach proposed, the catchment hydraulic response considers the rainfall conversion into runoff by means of a distributed model based on the 2D Shallow Water Equations (SWE). The infiltration losses are estimated by the SCS-Curve Number model or a Green-Ampt model modified via fractional calculus, termed Fractional Order Green-Ampt model (FOGA) (23, 24, 6] ). The combination of both surface and groundwater flow models allows to deal with infiltration/exfiltration processes that may occur when the water table reaches the soil surface, predicting a possible baseflow in the basin [25, 26, 27, 28, 29, 30]. This allows to evaluate the sensitivity of the outlet discharge hydrograph to the initial water table.

The catchment sedimentary response is also incorporated in the model. Solid transport is mathematically modeled by adding to the 2D SWE the sediment transport equation, both as suspended load and bed load separately. The suspended transport is modeled by non-equilibrium advective conservation laws for all the fractions involved allowing the net exchange between flow and bed (31, 32]). Furthermore, the bed load transport is addressed using the Exner equation using semi-empirical relationships to estimate the bed load discharge 80 ([1]).

The structure of the paper is as follows: An overview of surface flow, infiltration models, sediment transport laws and groundwater flow model, together with the coupling mechanisms is provided in section 2 , the numerical models are 
presented in section 3 together with analytical and laboratory validations test cases. Two real application cases (Arnás and Araguás catchments) are described in section 4 In section 5, the hydrological and geomorphological numerical results are contrasted to field measurements. Finally, the conclusions reached in this paper are presented. 


\section{Governing equations}

90 2.1. 2D Surface flow model with sediment transport

Free surface flows are usually described in Hydraulics by means of the depthaveraged 2D Shallow Water Equations (SWE), assuming that the vertical dimensions are small compared with the horizontal ones [33, 34]. Therefore, the pressure is assumed nearly hydrostatic and the horizontal velocity vector is uniform throughout the depth of the fluid. These equations represent water mass and momentum conservation along the horizontal direction of the flow and are a good description for many surface flow problems 33. When adding the sediment transport phenomena, additional equations should be considered representing the suspended sediment volume conservation for each fraction and the changes in the bed level due to erosion/deposition process. Furthermore, the vertical exchange flux between the sediment-laden flow and the erodible bed has to be taken into account. The hydrodynamical system of equations can be expressed in 2D, under the hypothesis of mild slope, as follows:

$$
\frac{\partial \mathbf{U}}{\partial t}+\frac{\partial \mathbf{F}}{\partial x}+\frac{\partial \mathbf{G}}{\partial y}=\mathbf{S}
$$

where

$$
\mathbf{U}=\left(h, q_{x}, q_{y}\right)^{T}
$$

105

are the hydrodynamical conserved variables with $h(m)$ representing the water depth (see Figure 1 and $q_{x}=h u$ and $q_{y}=h v$ the unit discharges $\left(m^{2} / s\right)$, with $u$ and $v$ the depth averaged components of the velocity vector $\mathbf{u}(\mathrm{m} / \mathrm{s})$ along the $x$ and $y$ coordinates, respectively. 


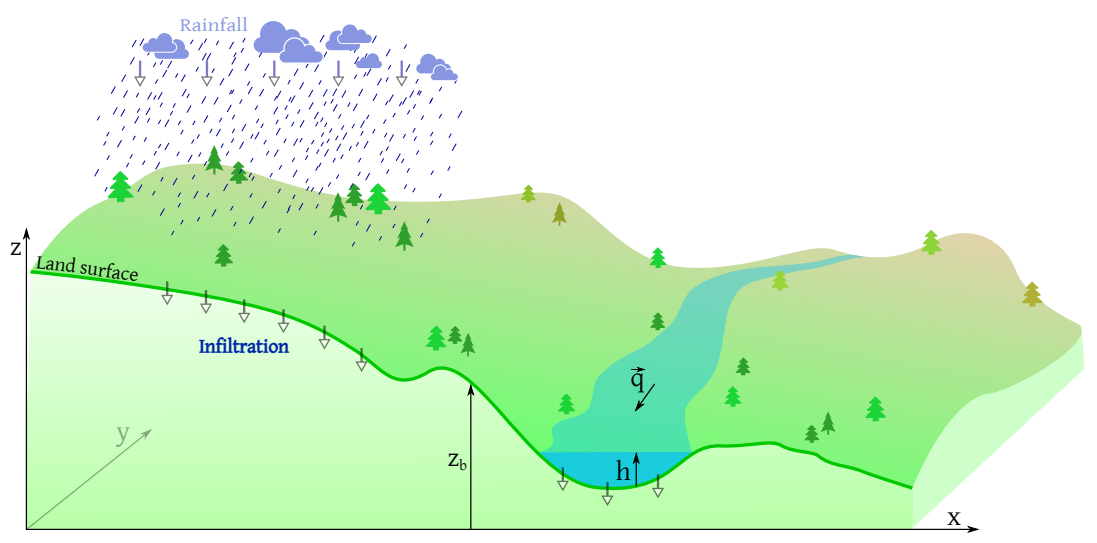

Figure 1: Coordinates representing water $\operatorname{depth} h$ and bed level $z$.

The fluxes of these conserved variables can be expressed as follows:

$$
\begin{gathered}
\mathbf{F}=\left(q_{x}, \frac{q_{x}^{2}}{h}+\frac{1}{2} g h^{2}, \frac{q_{x} q_{y}}{h}\right)^{T} \\
\mathbf{G}=\left(q_{y}, \frac{q_{x} q_{y}}{h}, \frac{q_{y}^{2}}{h}+\frac{1}{2} g h^{2}\right)^{T}
\end{gathered}
$$

where the acceleration due to gravity is represented with $g\left(\mathrm{~m} / \mathrm{s}^{2}\right)$.

The source term $\mathbf{S}$ on the right hand side of the equations is written as

$$
\mathbf{S}=\left(R-f-\xi \omega_{s}\left(\phi-\phi^{*}\right), g h\left(S_{0 x}-S_{f x}\right), g h\left(S_{0 y}-S_{f y}\right)\right)^{T}
$$

where the mass source term includes the rainfall intensity $R(\mathrm{~m} / \mathrm{s})$, the soil infiltration/exfiltration rate $f(\mathrm{~m} / \mathrm{s})$ and the net solid exchange flux between the flow and the static bed $\xi \omega_{s}\left(\phi-\phi^{*}\right)$, being $\omega_{s}$ the settling velocity of the solid particles $(\mathrm{m} / \mathrm{s}), \phi$ the actual depth-averaged volumetric concentration of the sediment transported in suspension, $\phi^{*}$ the equilibrium or capacity volumetric concentration for the suspended solid phase, $\xi=1 /(1-p)$ and $p$ the porosity of the bed layer.

The bed slopes along the $x$ and $y$ direction, $S_{0 x}$ and $S_{0 y}$ respectively, are 
given by:

$$
S_{0 x}=-\frac{\partial z_{b}}{\partial x}, \quad S_{0 y}=-\frac{\partial z_{b}}{\partial y}
$$

being $z_{b}$ the bed elevation $(m)$. The terms $S_{f x}, S_{f y}$ represent the energy slopes in both directions and can be expressed in terms of the bed shear stress components $\tau_{x}$ and $\tau_{y}(P a)$ :

$$
S_{f x}=\frac{\tau_{x}}{\rho g h}, \quad S_{f y}=\frac{\tau_{y}}{\rho g h}
$$

They are frequently modeled by the Manning's law in terms of the roughness coefficient $n\left(s m^{-1 / 3}\right)$ :

$$
\tau_{x}=\rho g h \frac{n^{2} u \sqrt{u^{2}+v^{2}}}{h^{4 / 3}}, \quad \tau_{y}=\rho g h \frac{n^{2} v \sqrt{u^{2}+v^{2}}}{h^{4 / 3}}
$$

that represents the turbulent shear stress at the fluid-bed interface.

Equation (1) has an hyperbolic character and thence it is possible to obtain a Jacobian matrix $\mathbf{J}_{n}$, built in terms of the flux in the normal direction $\mathbf{n}=$ $\left(n_{x}, n_{y}\right)$, defined as $\mathbf{E}_{n}=\mathbf{F} n_{x}+\mathbf{G} n_{y}$ :

$$
\mathbf{J}_{n}=\frac{\partial \mathbf{E}_{n}}{\partial \mathbf{U}}=\frac{\partial \mathbf{F}}{\partial \mathbf{U}} n_{x}+\frac{\partial \mathbf{G}}{\partial \mathbf{U}} n_{y}
$$

with the following eigenvalues:

$$
\lambda^{1}=\mathbf{u} \cdot \mathbf{n}+c, \quad \lambda^{2}=\mathbf{u} \cdot \mathbf{n}, \quad \lambda^{3}=\mathbf{u} \cdot \mathbf{n}-c
$$

and the corresponding eigenvectors:

$$
\mathbf{e}^{1}=\left(\begin{array}{c}
1 \\
u+c n_{x} \\
v+c n_{y}
\end{array}\right), \quad \mathbf{e}^{2}=\left(\begin{array}{c}
0 \\
-c n_{y} \\
c n_{x}
\end{array}\right), \quad \mathbf{e}^{3}=\left(\begin{array}{c}
1 \\
u-c n_{x} \\
v-c n_{y}
\end{array}\right)
$$

being $c=\sqrt{g h}$ the wave celerity $(\mathrm{m} / \mathrm{s})$. 
In this work, the suspended solid phase conservation is modeled by an advection equation, leaving aside the consideration concerning diffusion terms:

$$
\frac{\partial(h \phi)}{\partial t}+\frac{\partial}{\partial x}\left(q_{x} \phi\right)+\frac{\partial}{\partial y}\left(q_{y} \phi\right)=-\omega_{s}\left(\phi-\phi^{*}\right)
$$

where $h \phi$ is the suspended sediment volume in the flow column. Note that $\omega_{s} \phi$ represents the vertical deposition flux between the suspended solid phase and the static erodible bed layer, whereas $\omega_{s} \phi^{*}$ accounts for the entrainment flux into the suspended solid phase. The settling velocity $\omega_{s}$ and the capacity volumetric concentration can be estimated using semi-empirical formulations found in literature (see Section 2.3).

On the other hand, the evolution of the movable bed level $z_{b}$ is modeled by means of the continuity equation for the bed layer. Therefore, the changes in the bed level are caused by both the bedload solid transport and the net exchange flux between the static bed and the suspended solid phase [35, 36].

$$
\frac{\partial z_{b}}{\partial t}+\frac{\partial}{\partial x}\left(\xi q_{b, x}\right)+\frac{\partial}{\partial y}\left(\xi q_{b, y}\right)=\xi \omega_{s}\left(\phi-\phi^{*}\right)
$$

being $q_{b, x}$ and $q_{b, y}$ the bedload discharges $(\mathrm{m} / \mathrm{s})$ along the $x$ and $y$ directions, respectively, which are also estimated using semi-empirical relations found in literature (see Section 2.3).

\subsection{Infiltration models}

The process of soil infiltration is mainly governed by two forces: gravity and capillarity action. Most of the infiltration models formulate the infiltration capacity $f_{p}(\mathrm{~m} / \mathrm{s})$ and cumulative infiltration $F(m)$ in terms of the soil characteristic parameters.

It is important to remark the difference between $f_{p}$ and the actual infiltration rate $f$. In absence of surface water, a storm event starting with a rainfall intensity $R \leq f_{p}$ leads to a situation in which all the rain completely infiltrates into 
the soil. On the other hand, if $R>f_{p}$ the surface becomes ponded. Therefore:

$$
f(t)= \begin{cases}R(t) & \text { if } R(t) \leq f_{p}(t) \\ f_{p}(t) & \text { if } R(t)>f_{p}(t)\end{cases}
$$

The cumulative infiltration $F(t)$ can be computed by integrating in time the infiltration rate $f$ as:

$$
F(t)=\int_{0}^{t} f(t) d t
$$

\subsubsection{SCS Curve number model}

The Soil Conservation Service-Curve Number (SCS-CN) runoff model was originally developed by the USDA Natural Resources Conservation Service for estimating runoff from rainfall events on agricultural watersheds [37, 38]. Nowadays it is also used for urban hydrology. The main parameter of the method is the Curve Number $(\mathrm{CN})$ which is essentially a coefficient for reducing the total precipitation to runoff or surface water potential, by taking into account the losses. In general terms, the higher the $\mathrm{CN}$ value the higher the runoff potential.

Using the concepts of runoff or effective precipitation $R O(m)$, rainfall volume $R V(m)$, initial water abstraction which infiltrates before runoff begins $I_{a}$ $(m)$, the potential maximum retention $S(m)$ and the potential runoff, calculated as $R V-I_{a}$, the SCS-CN method is assumes equal relations between the real quantities and the potential quantities, as follows:

$$
\frac{F}{S}=\frac{R O}{R V-I_{a}}
$$

On the other hand, the surface water mass balance on the catchment can be expressed as:

$$
R V=R O+F+I_{a}
$$


By combining (16) and (17) and taking into consideration that the runoff cannot begin until the initial abstraction has been met:

$$
R O=\left\{\begin{array}{cc}
\frac{\left(R V-I_{a}\right)^{2}}{R V-I_{a}+S} & \left(R V>I_{a}\right) \\
0 & \left(R V \leq I_{a}\right)
\end{array}\right.
$$

The potential maximum retention $S$ is estimated (in $\mathrm{mm}$ ) by means of the Curve Number:

$$
S=\frac{25400}{C N}-254
$$

The initial abstraction is assumed proportional to $S$ :

$$
I_{a}=\sigma S
$$

where traditionally $\sigma=0.2$ for every watersheds [37] but recent studies suggest that there is a wide range of values that work better than this value, depending on the soil properties. The influence of this parameter was studied in [19].

It is important to remark that SCS-CN method was not designed to consider time. When the method is implemented in a time-advancing simulator, the runoff is calculated for every cell in every time step, using the cumulative rainfall since the beginning of the storm.

The SCS-CN method can be extended in order to estimate the temporal distribution of the water losses. By combining again $(16)$ and $(17)$ but solving for $F$ :

$$
F=\frac{S\left(R V-I_{a}\right)}{R V-I_{a}+S}, \quad R V \geq I_{a}
$$

By differentiating (21), taking into account that $I_{a}$ and $S$ are constant mag190 nitudes, the following expression for the infiltration rate is obtained [39]:

$$
f=\frac{d F}{d t}=\frac{S^{2} R}{R V-I_{a}+S}
$$

being $R=\frac{d R V}{d t}$ the rainfall rate. 


\subsubsection{Fractional Order Green-Ampt (FOGA) model}

The Green-Ampt model [40, 41, 39] considers a sharp wetting front at the position $z=s(t)$, as shown in Figure 2. This establishes a separation between the saturated soil region $0 \leq z \leq s(t)$ with a water content equal to the porosity $\theta_{s}$ and the unsaturated region $s(t)<z$ with an initial water content $\theta_{0}$. In addition, the water suction at the wetting front $(\Psi(m))$ is assumed to remain unmodified. Under these assumptions, the vertical hydraulic flux per unit area in the saturated area $q(\mathrm{~m} / \mathrm{s})$ is given by Darcy's law

$$
q=K_{s} \frac{\partial H}{\partial z}
$$

being $H(z, t)=\Psi+z(m)$ the hydraulic head and $K_{s}(\mathrm{~m} / \mathrm{s})$ the saturated hydraulic conductivity.

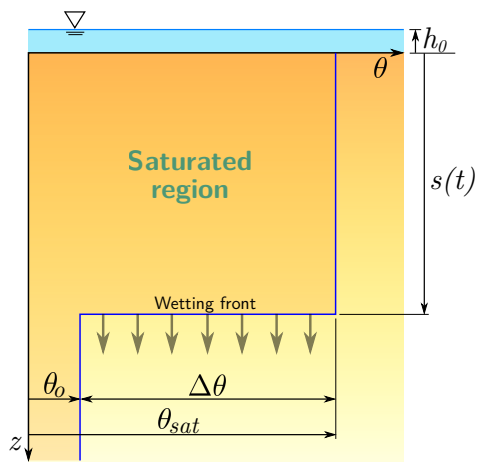

Figure 2: Sketch of the variables of the Green-Ampt infiltration wetting front.

A generalization of the Green-Ampt infiltration model is presented in 23] by considering the subsurface vertical hydraulic flux $q$ as a fractional-order derivative of $H$. Several empirical results were also reported in order to highlight some deviations of this infiltration model from the field measurements in heterogeneous soils and a generalized Darcy's law is used to improve the numerical results. Later on in [6] this modification of the Green-Ampt infiltration model was demonstrated useful to better fit the runoff discharge hydrograh when using infiltration as the only loss of rainfall water. As in the original Green-Ampt 
method, the vertical water movement is characterized using the flux:

$$
q=K_{\alpha} D_{z}^{\alpha} H, \quad D_{z}^{\alpha} \equiv \frac{D^{\alpha}}{D z^{\alpha}}
$$

where $K_{\alpha}$ is the hydraulic conductivity with the adequate dimensions for the fractional model $\left(m^{\alpha} / s\right)$. This provides the correct physical dimensions for the hydraulic flux [length/time]. Additionally, $D_{z}^{\alpha}$ represents the Caputo fractional derivative [42] of order $\alpha$ with $0<\alpha \leq 1$, defined by

$$
D_{z}^{\alpha} g(z, t)=\left[J^{1-\alpha}\left(\frac{\partial g}{\partial z}\right)\right](z, t)
$$

and

$$
\left(J^{1-\alpha} g\right)(z, t)=\frac{1}{\Gamma(1-\alpha)} \int_{r=0}^{z}(z-r)^{-\alpha} g(r, t) d r
$$

is the Riemann-Liouville fractional integral operator of order $1-\alpha$ where $\Gamma$ represents the Euler's Gamma function. It should be noted that if $\alpha=1$, then the derivative $D_{z}^{1}$ coincides with the partial derivative $\frac{\partial}{\partial z}$. Hence, the fractional-order Green-Ampt infiltration model (FOGA) can be considered as a generalization of the classical Green-Ampt method [42]

$$
f_{p}=\Delta \theta \frac{d s}{d t}=K_{\alpha} \Gamma(\alpha+1) \frac{s+\Psi-h_{0}}{s^{\alpha}}, \quad s(0)=0
$$

Table 1 shows a summary of the intermediate equations for both GA and FOGA models. Note that if $\alpha=1$, both GA and FOGA models are governed by the same differential equation. The full derivation of 27 can be found in [23] and 6]. 


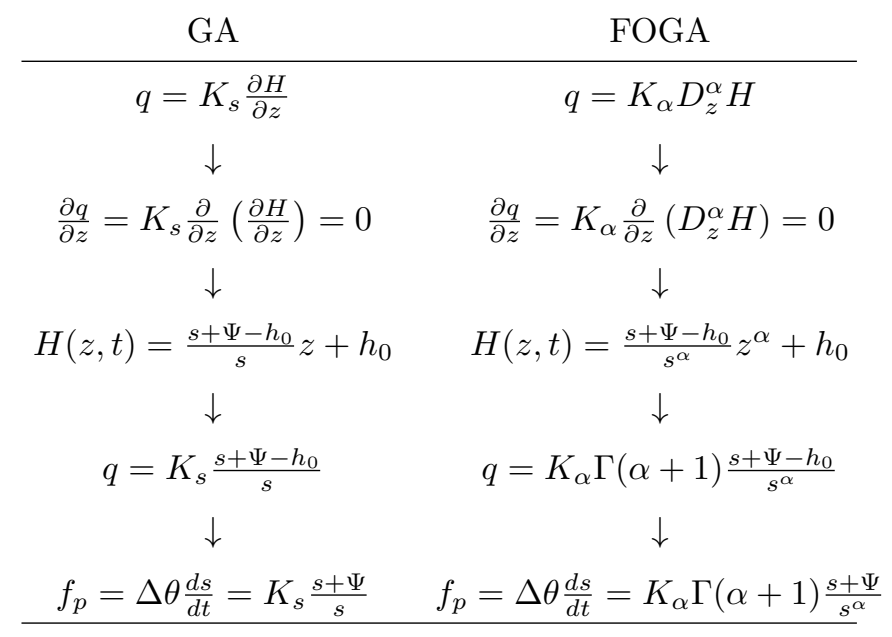

Table 1: Summary of GA and FOGA models.

In [6], a variable-order $\alpha$ of the fractional derivative is proposed, given in terms of the cumulative infiltration $F$ and the water depth $h$. This allows an order of the derivative $\alpha$ variable in time and distributed in space ( $x-y$ plane) with a different value for each cell:

$$
\alpha(F, h)=\min \left\{a F+\alpha_{\text {min }}, e^{b h}+\alpha_{\text {min }}-1,1\right\}
$$

where $a$ and $b$ are constant values to calibrate and $\alpha_{\min }$ is the minimum value that the order of the derivative can reach. Then, it holds that $\alpha_{\min } \leq \alpha(F, h) \leq$ 1.

\subsection{Sediment transport laws}

Two different sediment transport processes are considered in this work, suspended transport and bedload transport, and both may coexist and exchange with the static bed layer. The bed load transport is often represented by the dimensionless number $\Phi$ :

$$
\Phi=\frac{\left|q_{b}\right|}{\sqrt{g(s-1) d_{50}^{3}}}
$$


where $s=\rho_{s} / \rho_{w}$ is the specific density of the solid material $\left(\rho_{s}\left(\mathrm{~kg} / \mathrm{m}^{3}\right)\right)$ with respect to the water $\left(\rho_{w}\left(\mathrm{~kg} / \mathrm{m}^{3}\right)\right), d_{50}$ is the median diameter of bed particles $(m)$ and $\left|q_{b}\right|=\sqrt{q_{b, x}^{2}+q_{b, y}^{2}}$ is the bedload discharge.

On the other hand, for the cases where the stress is governed by Manning's law, the flow shear stress is formulated using the dimensionless Shields number $\theta$ :

$$
\theta=\frac{n^{2}}{(s-1) d_{50} h^{1 / 3}}|\mathbf{u}|^{2}
$$

Both $\Phi$ and $\theta$ can be related using empirical laws found in literature. In this work, the Smart formula [43] is used as it includes the influence of the bed slope 44.

$$
\Phi=4\left(\frac{d_{90}}{d_{30}}\right)^{0.2} S_{0}^{0.6} \frac{h^{1 / 6}}{g^{1 / 2} n} \theta^{1 / 2}\left(\theta-\theta_{c}^{S}\right)
$$

where $d_{90}$ and $d_{30}$ are the grain diameters for which $90 \%$ and $30 \%$ of the weight of the material is finer, respectively, and $\theta_{c}^{S}$ is defined as follows:

$$
\theta_{c}^{S}=\theta_{c} \cos \beta\left(1-\frac{\tan \beta}{\tan \psi}\right)
$$

with $\theta_{c}=0.047$ is the critical Shields value for the incipient motion, $\beta$ is the bed slope angle respect to the horizontal plane and $\psi$ is the internal equilibrium angle for the bed solid material. Hence, the bedload solid discharge $\left|q_{b}\right|$ can be calculated by combining (29) and (30), leading to the following expression [35]:

$$
\left|q_{b}\right|=K_{0} K_{1}|\mathbf{u}|^{3}
$$

with:

$$
K_{0}=\frac{g^{1 / 2} n^{3}}{(s-1) h^{1 / 2}}, \quad K_{1}=4\left(\frac{d_{90}}{d_{30}}\right)^{0.2} S_{0}^{0.6} \frac{h^{1 / 6}}{n}\left(1-\theta_{c}^{S} / \theta\right)
$$

and the bedload fluxes along the $x$ and $y$ directions in $(13)$ can be expressed as:

$$
q_{b, x}=K_{0} K_{1}|\mathbf{u}|^{2} u \quad q_{b, y}=K_{0} K_{1}|\mathbf{u}|^{2} v
$$


Regarding the net exchange flux between the suspended solid phase and the bed layer, $\omega_{s}\left(\phi-\phi^{*}\right)$, the settling velocity $\omega_{s}$ can be estimated by means of several laws as a function of the sediment density and grain diameter. In this work, this magnitude is estimated with Zhang's formula [45] due its validity for a wide range of particle diameter:

$$
\omega_{s}=\sqrt{\left(13.95 \frac{\nu}{d_{50}}\right)^{2}+1.09(s-1) g d_{50}}-13.95 \frac{\nu}{d_{50}}
$$

being $\nu$ the water viscosity. On the other hand, the equilibrium concentration $\phi^{*}$ for the suspended solid phase can be computed as follows:

$$
\phi^{*}= \begin{cases}0 & \theta<\theta_{c} \\ q_{s} /(h|\mathbf{u}|) & \theta \geq \theta_{c}\end{cases}
$$

where the suspended solid discharge $q_{s}$ is computed in this work by means of the Van Rijn's formula [46]:

$$
q_{s}=\int_{h_{\text {sed }}}^{h} \phi_{m}|\mathbf{u}| d h^{\prime}
$$

being:

$$
\begin{gathered}
h_{\text {sed }}=0.3 d_{50}\left[d_{50}\left(\frac{(s-1) g}{\nu^{2}}\right)^{1 / 3}\right]^{0.7} \sqrt{\frac{\theta}{\theta_{c}}-1} \\
\phi_{m}=\phi_{s}\left(\frac{\frac{h}{h^{\prime}}-1}{\frac{h}{h_{s e d}}-1}\right)^{\omega_{s} /\left(k U_{*}\right)}
\end{gathered}
$$

with $U_{*}=\sqrt{\frac{g n^{2}|\mathbf{u}|^{2}}{h^{1 / 3}}}$ representing the friction velocity, $k \simeq 0.41$ the Von-Karman 265 constant and $\phi_{s}$ defined as follows:

$$
\phi_{s}=\frac{0.117}{d_{50}}\left[\frac{\nu^{2}}{(s-1) g}\right]^{1 / 3}\left(\frac{\theta}{\theta_{c}}-1\right)
$$




\subsection{D Groundwater flow model}

In this work, the 2D groundwater flow is formulated by means of Darcy's law for saturated flow in porous media [47]. This equation establishes the relationship among the groundwater discharge $\mathbf{q}_{s u b}\left(\mathrm{~m}^{2} / \mathrm{s}\right)$ and the horizontal hydraulic gradient $\nabla h_{s}$ as follows:

$$
\mathbf{q}_{s u b}=-K_{s}\left(h_{s}-z_{s}\right) \nabla h_{s}
$$

where $h_{s}(m)$ is the soil pressure height and $z_{s}(m)$ the vertical distance from datum to the boundary between impervious and saturated regions (see Figure 3 for the coordinate system of the groundwater flow model).

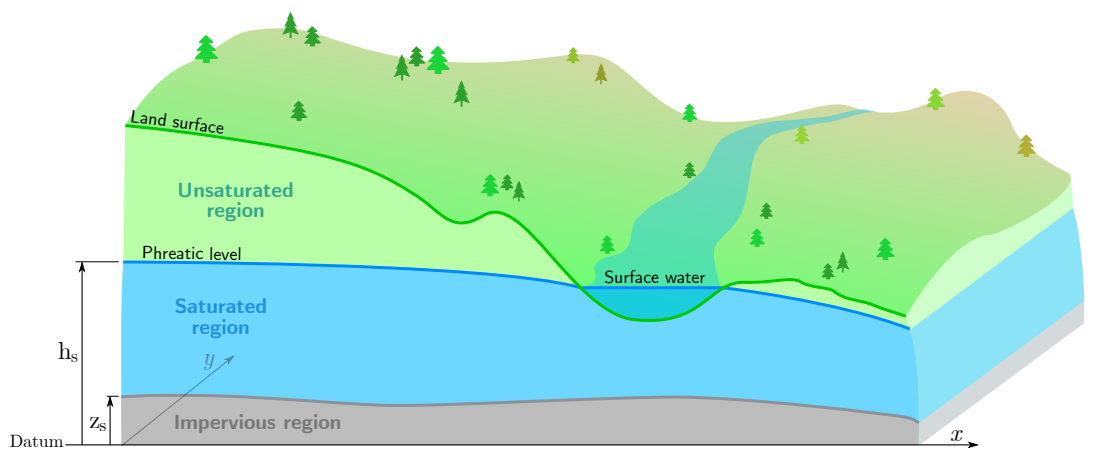

Figure 3: Subsurface coordinate system.

By combining 42 with the continuity equation for flows in porous media

$$
\eta \frac{\partial\left(h_{s}-z_{s}\right)}{\partial t}+\nabla \mathbf{q}_{s u b}=S_{s}
$$

we obtain

$$
\eta \frac{\partial h_{s}}{\partial t}-K_{s} \nabla\left[\left(h_{s}-z_{s}\right) \nabla h_{s}\right]=S_{s}
$$

where $\eta$ represents the saturated layer porosity and $S_{s}$ the mass source terms $(\mathrm{m} / \mathrm{s})$. 


\section{Numerical models}

\subsection{Surface flow with sediment transport}

The 2D Shallow Water equations (1) conform a hyperbolic non-linear system that can also be written using a general conservative formulation:

$$
\frac{\partial \mathbf{U}}{\partial t}+\nabla \cdot \mathbf{E}=\mathbf{S}
$$

with $\mathbf{E}=(\mathbf{F}, \mathbf{G})$.

Equation 45 is integrated over a control volume $\Omega$ :

$$
\frac{d}{d t} \int_{\Omega} \mathbf{U} d \Omega+\int_{\Omega}(\nabla \cdot \mathbf{E}) d \Omega=\int_{\Omega} \mathbf{S} d \Omega
$$

Invoking Gauss' theorem, dividing the spatial domain in computational cells

$i$ of area $A_{i}$ with $N_{w}$ polygonal faces of lenght $l_{w}$, each with an outer-pointing normal vector $\mathbf{n}_{w}$ (see Figure 4 ) and applying the forward Euler method for the time derivative in terms of the time step size $\Delta t$ :

$$
\frac{\mathbf{U}_{i}^{n+1}-\mathbf{U}_{i}^{n}}{\Delta t} A_{i}+\sum_{w=1}^{N_{w}}(\delta \mathbf{E} \cdot \mathbf{n})_{w}^{n-} l_{w}=\sum_{w=1}^{N_{w}} \mathbf{S}_{w}^{n} l_{w}
$$
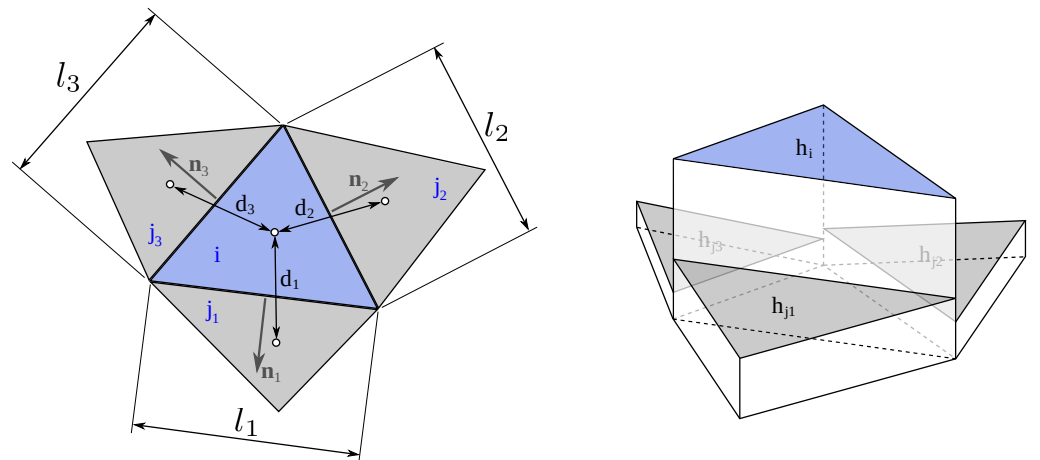

Figure 4: Cell connectivity sketch in a triangular unstructured mesh.

The focus in (47) is put on the flux and source terms contributions defined at the grid edges $w$. The difference in vector $\mathbf{U}$ across the grid edge and the 
source term can be projected onto the matrix eigenvectors basis, as follows:

$$
\delta \mathbf{U}_{w}=\mathbf{U}_{j}-\mathbf{U}_{i}=\tilde{\mathbf{P}}_{w} \mathbf{A}_{w}, \quad \mathbf{S}_{w}=\frac{1}{2}\left(\mathbf{S}_{i}+\mathbf{S}_{j}\right)=\tilde{\mathbf{P}}_{w} \mathbf{B}_{w}
$$

being $\mathbf{A}$ and $\mathbf{B}$ the wave and source strength vectors, given by:

$$
\mathbf{A}_{w}=\left(\alpha^{1}, \alpha^{2}, \alpha^{3}\right)_{w}^{T}, \quad \mathbf{B}_{w}=\left(\beta^{1}, \beta^{2}, \beta^{3}\right)_{w}^{T}
$$

Then, the flux and source terms in 46 can be expressed in terms of the approximate eigenvalues $\tilde{\lambda}_{w}^{m}$ and eigenvectors $\tilde{\mathbf{e}}_{w}^{m}$, where $m=1,2,3$ as follows:

$$
\begin{gathered}
\delta(\mathbf{E} \cdot \mathbf{n})_{w}=\mathbf{J}_{n} \delta \mathbf{U}_{w}=\sum_{m=1}^{3}(\tilde{\lambda} \alpha \tilde{\mathbf{e}})_{w}^{m}, \\
\mathbf{S}_{w}=\sum_{m=1}^{3}(\beta \tilde{\mathbf{e}})_{w}^{m}
\end{gathered}
$$

In this work, an explicit temporal scheme is considered for the surface flow. in (47):

$$
\mathbf{U}_{i}^{n+1}=\mathbf{U}_{i}^{n}-\frac{\Delta t}{A_{i}} \sum_{w=1}^{N_{w}} \sum_{m=1}^{3}(\tilde{\lambda} \alpha \tilde{\mathbf{e}}-\beta \tilde{\mathbf{e}})_{w}^{m, n}
$$

Equation 12 can be also integrated in a control volume $\Omega$ and modified by means of the Gauss theorem:

$$
\frac{d}{d t} \int_{\Omega} h \phi d \Omega+\int_{\partial \Omega} q_{\mathbf{n}} \phi \partial \Omega=-\int_{\Omega} \omega_{s}\left(\phi-\phi^{*}\right) d \Omega
$$

being $q_{\mathbf{n}}=q_{x} n_{x}+q_{y} n_{y}$. Therefore, the conserved variable $h \phi$ is updated as 300 follows:

$$
(h \phi)_{i}^{n+1}=(h \phi)_{i}^{n}-\frac{\Delta t}{A_{i}} \sum_{w=1}^{N_{w}}\left(q_{\mathbf{n}} \phi\right)_{w}^{\downarrow} l_{w}-\Delta t \omega_{s}\left(\phi_{i}-\phi_{i}^{*}\right)^{n}
$$


where $\left(q_{\mathbf{n}} \phi\right)_{w}^{\downarrow}$ is the numerical solid phase flux at the cell edge, computed as:

$$
\left(q_{\mathbf{n}} \phi\right)_{w}^{\downarrow}= \begin{cases}q_{\mathbf{n}, w}^{\downarrow} \phi_{i} & \text { if } q_{\mathbf{n}, w}^{\downarrow}>0 \\ q_{\mathbf{n}, w}^{\downarrow} \phi_{j} & \text { if } q_{\mathbf{n}, w}^{\downarrow}<0\end{cases}
$$

being $q_{\mathbf{n}, w}^{\downarrow}$ the augmented numerical flux for the hydrodynamical flow at the cell edge, computed using (50) and (51) as:

$$
q_{\mathbf{n}, w}^{\downarrow}=q_{\mathbf{n}, i}-\sum_{m^{-}}\left(\tilde{\lambda} \alpha \tilde{\mathbf{e}_{1}}-\beta \tilde{\mathbf{e}_{1}}\right)_{w}^{m}
$$

where $q_{\mathbf{n}, i}$ is the hydrodynamical normal flux at the left cell $i$ and $m^{-}$indicates the waves going to left direction $\left(\tilde{\lambda}_{w}<0\right)$.

By following the same procedure for Equation (13):

$$
\frac{d}{d t} \int_{\Omega} z_{b} d \Omega+\int_{\partial \Omega} \xi q_{b, \mathbf{n}} \partial \Omega=\int_{\Omega} \xi \omega_{s}\left(\phi-\phi^{*}\right) d \Omega
$$

being $q_{b \mathbf{n}}=q_{b, x} n_{x}+q_{b, y} n_{y}$. Hence:

$$
z_{b, i}^{n+1}=z_{b, i}^{n}-\frac{\Delta t}{A_{i}} \sum_{w=1}^{N_{w}} \xi q_{b \mathbf{n}, w}^{\downarrow} l_{w}+\Delta t \xi \omega_{s}\left(\phi_{i}-\phi_{i}^{*}\right)^{n}
$$

where the numerical bedload flux at the cell edge $q_{b \mathbf{n}, w}^{\downarrow}$ is computed using an upwind scheme:

$$
q_{b \mathbf{n}, w}^{\downarrow}= \begin{cases}q_{b \mathbf{n}, i} & \text { if } \tilde{\lambda}_{b}>0 \\ q_{b \mathbf{n}, j} & \text { if } \tilde{\lambda}_{b}<0\end{cases}
$$

$j$ cells, respectively, and $\tilde{\lambda}_{b}$ the numerical bedload celerity at the cell edge, computed as follows:

$$
\tilde{\lambda}_{b}=\frac{\xi\left(q_{b \mathbf{n}, j}-q_{b \mathbf{n}, i}\right)}{z_{j}-z_{i}}
$$

This numerical bedload celerity $\tilde{\lambda}_{b}$ is not a true celerity in strict sense as Exner equation is not hyperbolic but it allows to build a weakly coupled method 315 that has been shown to work properly even for highly erosive flows [36]. 
As the temporal discretization is explicit, the time step choice must guarantee the stability of the numerical solution. Here, $\Delta t$ it is dynamically chosen as follows:

$$
\Delta t=\mathrm{CFL} \min _{M e s h}\left(\Delta t_{i, w}\right)
$$

where CFL is the Courant-Friedrichs-Levy number, restricted to $\mathrm{CFL}=0.5$ in rectangular grids and to $\mathrm{CFL} \leq 1$ in unstructured triangular meshes, and

$$
\Delta t_{i, w}=\frac{\min \left(\Delta x_{i}^{\prime}, \Delta x_{j}^{\prime}\right)}{\max _{m=1,2,3}\left(\left|\tilde{\lambda}_{w}^{m}, \tilde{\lambda}_{b}\right|\right)}, \quad \Delta x_{i}^{\prime}=\frac{S_{i}}{\max _{1, N_{w}}\left(l_{w}\right)}
$$

Further details on this numerical scheme and additional considerations such as entropy fixes, source terms limitations and wet-dry treatment can be found in [34.

\subsection{Groundwater flow}

Equation (44) has a parabolic character and is numerically solved over an arbitrary spatial discretization by means of an implicit finite volume scheme for the sake of efficiency. The characteristic slow transients of the groundwater flow makes the implicit discretization the optimal choice for these kind of models. By integrating (44) over a fixed control volume $\Omega$ :

$$
\int_{\Omega} \eta \frac{\partial h_{s}}{\partial t} d \Omega=\int_{\Omega} K_{s} \nabla\left[\left(h_{s}-z_{s}\right) \nabla h\right] d \Omega+\int_{\Omega} S_{s} d \Omega
$$

Assuming $\eta$ and $K_{s}$ constant in time and uniform at every computational cell:

$$
\begin{aligned}
\eta \frac{h_{s}^{n+1}-h_{s}^{n}}{\Delta t} \Omega= & \gamma K_{s} \int_{\partial \Omega}\left[\mathbf{f}^{n+1}\left(h_{s}\right) \mathbf{n}\right] \partial \Omega+ \\
& (1-\gamma) K_{s} \int_{\partial \Omega}\left[\mathbf{f}\left(h_{s}\right)^{n} \mathbf{n}\right] \partial \Omega+S_{s} \Omega
\end{aligned}
$$

where the temporal discretization is done in terms of the weight $\gamma$. The value $(\gamma=1)$ leads to a fully-implicit scheme, the one used in the present work. The value $(\gamma=0)$ would recover a fully-explicit method. 
The flux of this model $\mathbf{f}=\left(h_{s}-z_{s}\right) \nabla h_{s}$ is a non-linear function of $h_{s}$. Considering the control volume $\Omega$ as equal to a finite volume $A_{i}$ of the cell $i$ with $N_{w}$ polygonal faces of lenght $l_{w}$, each with an outer-pointing normal vector $\mathbf{n}_{w}$ and distance between centroids of the cells $i$ and $j$ defined as $d_{w}$ (see Figure 4):

$$
\begin{aligned}
\eta \frac{h_{s, i}^{n+1}-h_{s, i}^{n}}{\Delta t} A_{i}= & \gamma K_{s} \sum_{j, w=1}^{N_{w}}\left(h_{s, w}^{n+1}-z_{s, w}\right) \frac{h_{s, j}^{n+1}-h_{s, i}^{n+1}}{d_{w}} l_{w}+ \\
& (1-\gamma) K_{s} \sum_{j, w=1}^{N_{w}}\left(h_{s, w}^{n}-z_{s, w}\right) \frac{h_{s, j}^{n}-h_{s, i}^{n}}{d_{w}} l_{w}+S_{s, i} A_{i}
\end{aligned}
$$

This requires a linearization which is done by means of the fixed-point Picard iterations, evaluating the fluxes at an intermediate step (iteration) $m$ :

$$
\begin{aligned}
h_{s, i}^{n+1, m+1}-h_{s, i}^{n}= & \gamma \frac{K_{s} \Delta t}{\eta A_{i}} \sum_{j, w=1}^{N_{w}}\left(h_{s, w}^{n+1, m}-z_{s, w}\right) \frac{h_{s, j}^{n+1, m+1}-h_{s, i}^{n+1, m+1}}{d_{w}} l_{w}+ \\
& (1-\gamma) \frac{K_{s} \Delta t}{\eta A_{i}} \sum_{j, w=1}^{N_{w}}\left(h_{s, w}^{n}-z_{s, w}\right) \frac{h_{s, j}^{n}-h_{s, i}^{n}}{d_{w}} l_{w}+\frac{\Delta t}{n} S_{s, i}
\end{aligned}
$$

The next step is to reorder equation (66). For simplicity of notation, temporal indices will not be shown:

$$
h_{s, w}^{n+1, m} \equiv h_{w}^{m}, \quad h_{s, i}^{n+1, m+1} \equiv h_{s, i}^{m+1}, \quad h_{s, j}^{n+1, m+1} \equiv h_{s, j}^{m+1}
$$

Hence, whenever $m$ or $m+1$ superindices are shown, it refers to time $n+1$ in the corresponding iteration. By reordering and rewriting in a compact coefficient form:

$$
a_{i} h_{s, i}^{m+1}+\sum_{j, w=1}^{N_{w}} b_{w} h_{s, j}^{m+1}=c_{i}
$$


where

$$
\begin{gathered}
a_{i}=1+\gamma \frac{K_{s} \Delta t}{\eta A_{i}} \sum_{w=1}^{N_{w}}\left(h_{s, w}^{m}-z_{s, w}\right) \frac{l_{w}}{d_{w}} \\
b_{w}=-\gamma \frac{K_{s} \Delta t}{\eta A_{i}}\left(h_{s, w}^{m}-z_{s, w}\right) \frac{l_{w}}{d_{w}} \\
c_{i}=h_{i}^{n}+(1-\gamma) \frac{K_{s} \Delta t}{\eta A_{i}} \sum_{j, w=1}^{N_{w}}\left(h_{s, w}^{n}-z_{s, w}\right) \frac{l_{w}}{d_{w}}\left(h_{s, j}-h_{s, i}\right)+\frac{\Delta t}{\eta} S_{s, i}
\end{gathered}
$$

Expressions (68) to (71) represent a system of equations conforming a $N \times N$ 350 matrix, being $N$ the number of computational cells. For a structured rectangular mesh (Figure 5, left), this results in a penta-diagonal matrix, as follows:

$$
\left(\begin{array}{cccccccc}
a_{1} & b_{w} & & b_{w} & & & \\
b_{w} & a_{2} & b_{w} & & b_{w} & & & \\
& b_{w} & a_{3} & b_{w} & & \ddots & & \\
\ddots & & \ddots & \ddots & \ddots & & \ddots & \\
& b_{j 1} & & b_{j 4} & a_{i} & b_{j 2} & & b_{j 3} \\
& & \ddots & & \ddots & \ddots & \ddots & \\
& & & \ddots & & b_{w} & a_{N-1} & b_{w} \\
& & & & b_{w} & & b_{w} & a_{N}
\end{array}\right)\left(\begin{array}{c}
h_{s, 1} \\
h_{s, 2} \\
h_{s, 3} \\
\vdots \\
h_{s, i} \\
\vdots \\
h_{s, N-1} \\
h_{s, N}
\end{array}\right)=\left(\begin{array}{c}
c_{1} \\
c_{2} \\
c_{3} \\
\vdots \\
c_{i} \\
\vdots \\
c_{N-1} \\
c_{N}
\end{array}\right)
$$

whereas an unstructured triangular mesh (Figure 5, right) generates a nonstructured matrix in which the population depends on the mesh neighbour con- 
nectivity:

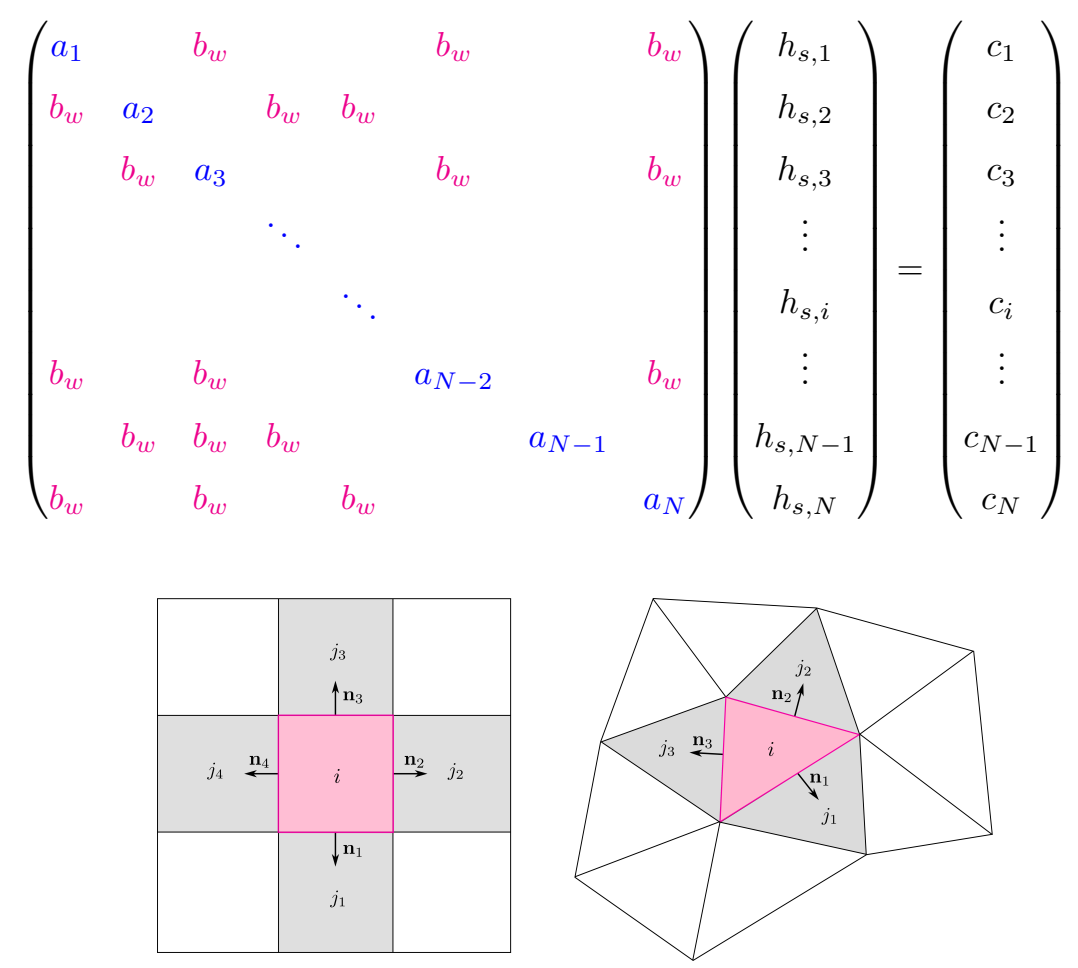
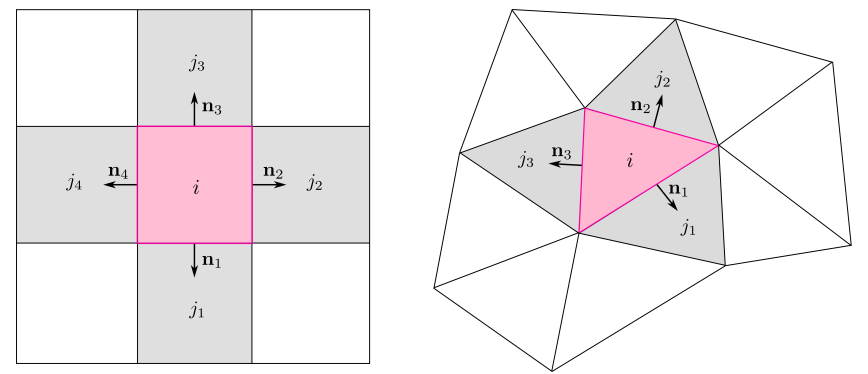

Figure 5: Inner cells for structured rectangular (left) and unstructured triangular (right) meshes.

The linear system conformed by the matrix and the right-hand-side vector needs to be solved by means of a matrix inversion technique. In this work, BiConjugate Gradient Stabilized (BiCGStab) solver [48, 49] has been used. This solver takes a great advantage of the use of sparse storage strategies for non symmetric matrices, avoiding the storage of the null elements and, therefore, reducing the computational cost and the memory requirements, which is an important issue due to the usually huge size of the matrix. A dual threshold Incomplete LU factorization (ILUT) [50] is used as matrix preconditioner.

As the numerical scheme used for the groundwater flow follows an implicit methodology, it benefits from theoretical unconditional stability regardless of the time step choice. In general, larger time steps do not necessarily imply 
faster simulations when solving a nonlinear problem [51, 52]. A large time step usually means that the solution process (linearization + matrix inversion) requires a high number of iterations to achieve convergence. On the other hand, the implicit scheme provides a great freedom of choice of the time step for the groundwater flow and its linking with the surface flow computation, as shown in the next section.

\subsection{Surface and groundwater model coupling mechanisms}

The overland and groundwater flow models are coupled in two ways. First, the water exchange at the soil surface is computed by means of the infiltration rate $f$ from the surface. Water from rainfall or surface flow infiltrates and may recharge the phreatic level (PL), as shown in Figure 6. The phreatic level is therefore updated with a temporal delay $t^{\prime}$ estimated as $t^{\prime}=\frac{z_{b}-h_{s}}{K_{n s}}$, that is the ratio between the vertical distance between the soil surface and the current position of the PL and the hydraulic conductivity of the vadose zone $K_{n s}$, which is assumed to be equal to $K_{s}$ as a first approximation.

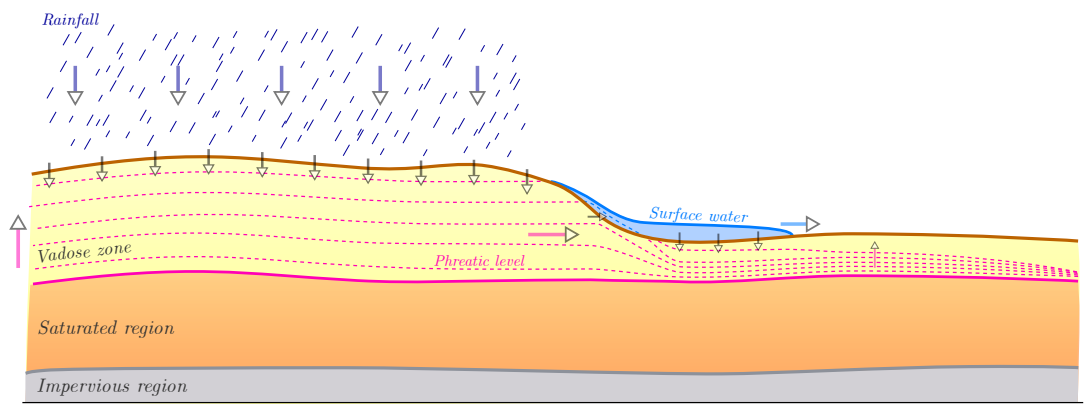

Figure 6: Phreatic level recharging and water exchange in a typical surface-groundwater interaction

On the other hand, a horizontal flux across a vertical facet of each computational cell pair may appear depending on the difference between surface water level and phreatic surface. If the surface water level $h_{i}+z_{b, i}$ of the cell $i$ exceeds the phreatic level $h_{s, j}$ of the neighbour cell $j$, infiltration through the common wall occurs (Figure 7, a). This will occur regardless of whether the cell $j$ has 
surface water or not, provided that $h_{s, j}<z_{b, j}$ (Figure 7, b). On the contrary, if the phreatic surface $h_{s, j}$ exceeds the water level value $h_{i}+z_{b, i}$ exfiltration occurs regardless of the value of $h_{i}$ (Figure $7, \mathrm{c}, \mathrm{d}$ ). The infiltration/exfiltration flux is combined with the groundwater flow equation 68 as a source term $S_{s, i}$ and its value is estimated using Darcy's law:

$$
S_{s, i}=-K_{s} \sum_{w=I E} \frac{\Delta H_{w}}{d_{w}}
$$

being $\Delta H_{w}=h_{i}+z_{b, i}-h_{s, j}$ the head difference across every facet $w=I E$ susceptible to exchange flow between surface and subsurface. If $\Delta H_{w}>0$ infiltration occurs across the cell facet whereas $\Delta H_{w}<0$ implies exfiltration. The total flow exchange for each cell $i$ is computed as the sum of the contributions of all the cell facets.

Figure 8 shows a schematic flowchart with the main steps of the simulation for the surface-groundwater coupled model.

a)
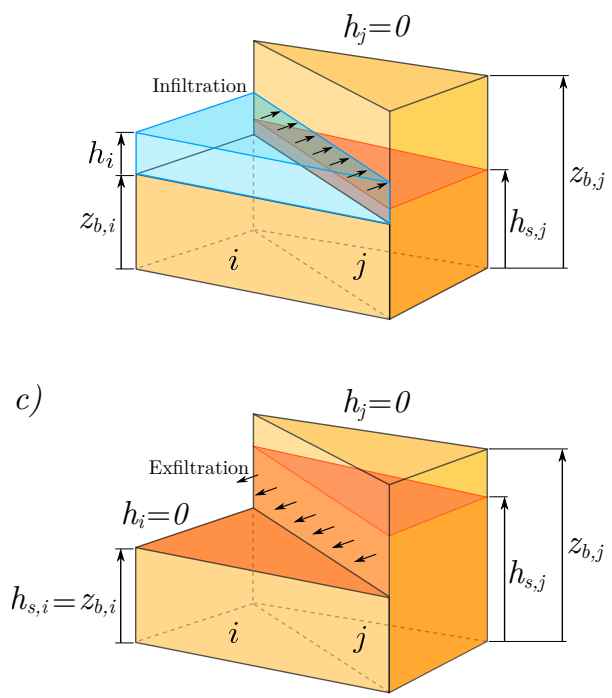

b)

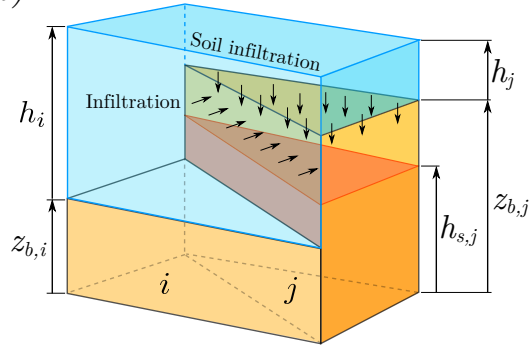

d)

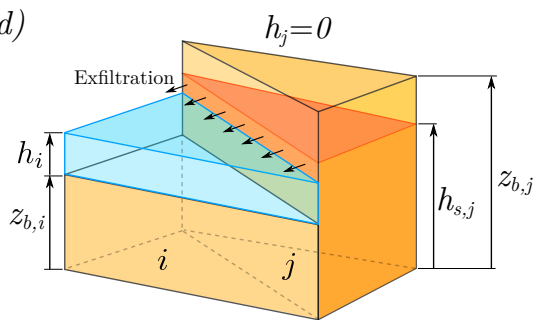

Figure 7: Infiltration (a, b) and exfiltration (c, d) exchange processes. 


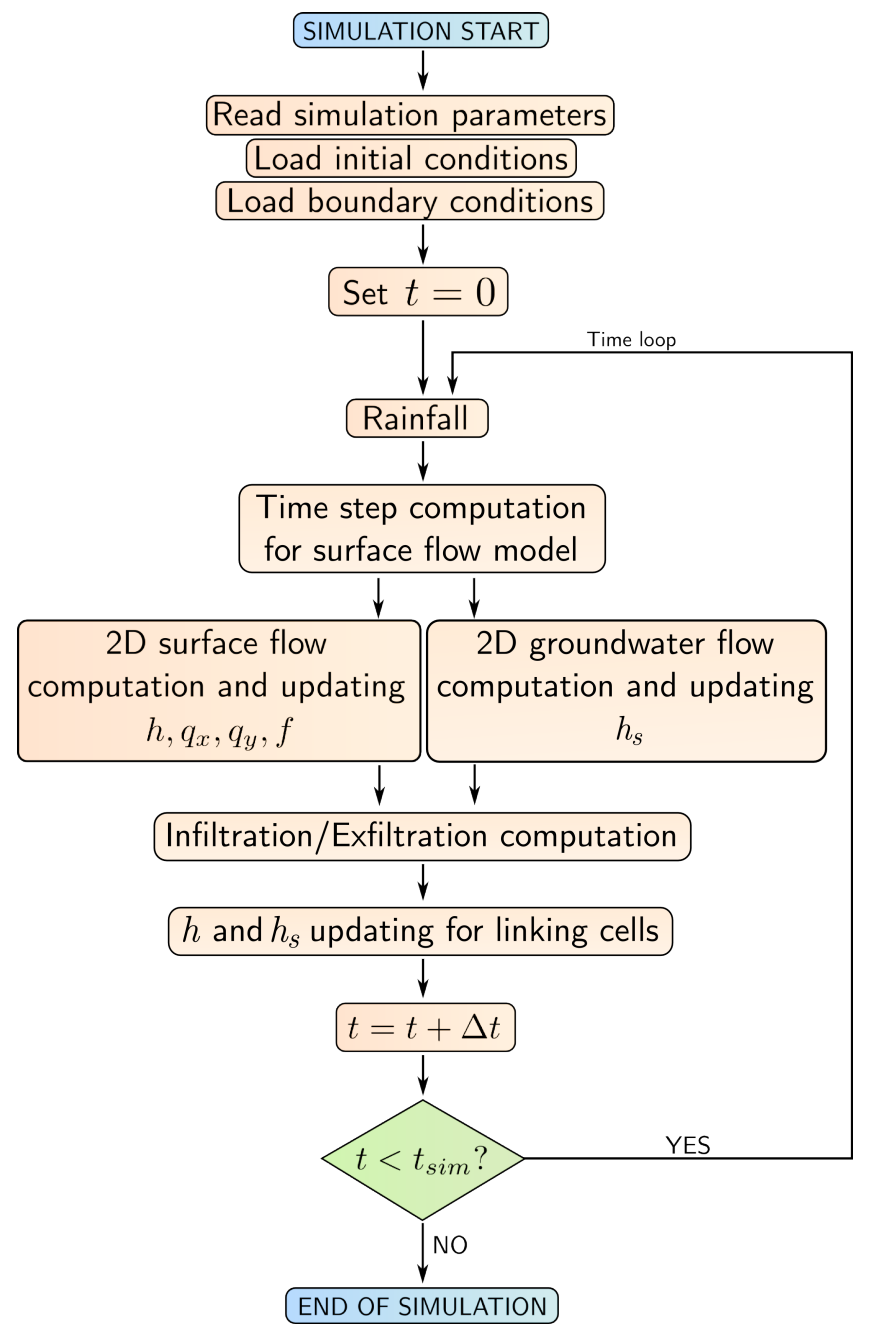

Figure 8: Surface-Groundwater coupled model flowchart. 
In order to reduce the computational cost of the simulations a time step optimization strategy has been implemented. Since the groundwater flow is expected to be much slower that the overland flow and the model benefits from the inconditional stability of the implicit scheme, larger subsurface time steps shall be used. Both surface and subsurface model communicate every $N$-th surface time steps, as shown in Figure 9 .

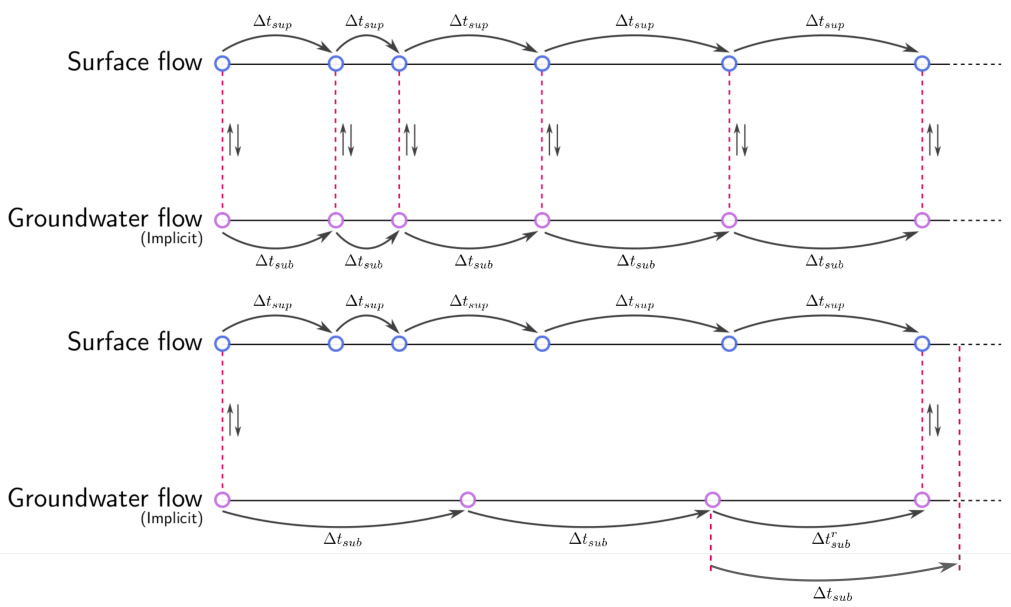

Figure 9: Same time step value for both surface and subsurface models (upper). Establishing the communication after $N$ implicit time steps (lower).

\subsection{D test case with analytical solution}

Let us consider a porous media with uniform values of saturated hydraulic conductivity $\left(K_{s}=1.25 \mathrm{~cm} / \mathrm{s}\right)$ and porosity $(\eta=0.4)$. A first configuration is set (Setup 1) where a water level of $h_{s}=22.2 \mathrm{~cm}$ and $0 \mathrm{~cm}$ are imposed as inlet and outlet boundary conditions, respectively, of a $1 \mathrm{~m}$ lenght domain (see Figure 10. upper). A second configuration (Setup 2) is considered by adding a slope to the impervious region frontier. In this case, the imposed inlet water level is $h_{s}=35 \mathrm{~cm}$ (Figure 10, lower).

In both cases, the steady analytical solution can be easily found by solving the Darcy's equation with the appropiate boundary values. Equations 75 

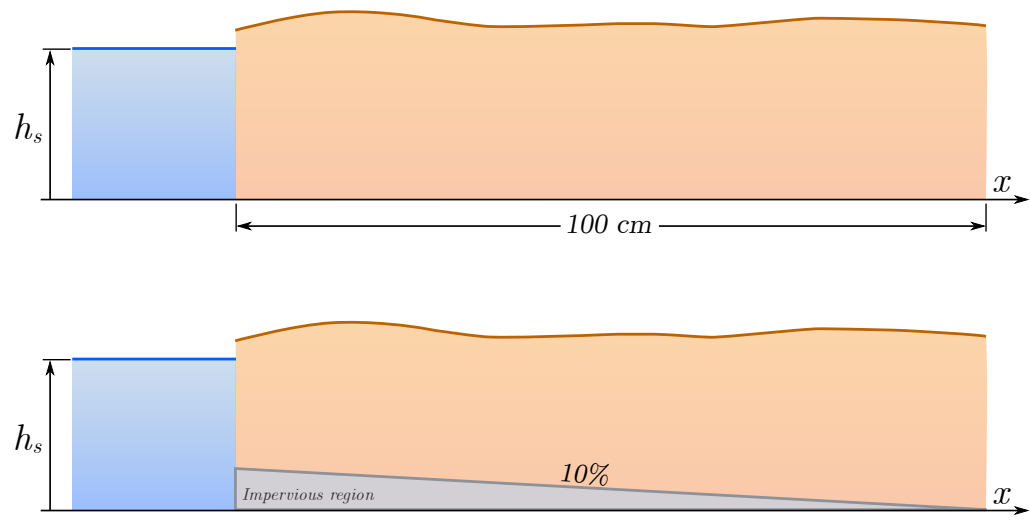

Figure 10: Sketch of 1D test case for groundwater flow. Setups 1 (upper) and 2 (lower).

and (76) show the exact solutions for $h_{s}(x)$ in $\mathrm{cm}$ for the case setups 1 and 2, respectively:

$$
\begin{gathered}
h_{s}(x)=\sqrt{492.84-4.93 x} \\
x+\frac{h_{s}}{m}+\frac{A}{m^{2}} \ln \left(m h_{s}-A\right)=B
\end{gathered}
$$

where $m=-0.1$ represents the impervious region slope and $A=-4.89 \mathrm{~cm}$, $B=-676.78 \mathrm{~cm}$ and two constant coefficients.

Figures 11 and 12 show the convergence of the transient numerical solution to the steady state. In both cases, a perfect fit to the exact solution is achieved. ${ }_{420}$ Both explicit and implicit numerical schemes provide exactly the same steady numerical solution. 


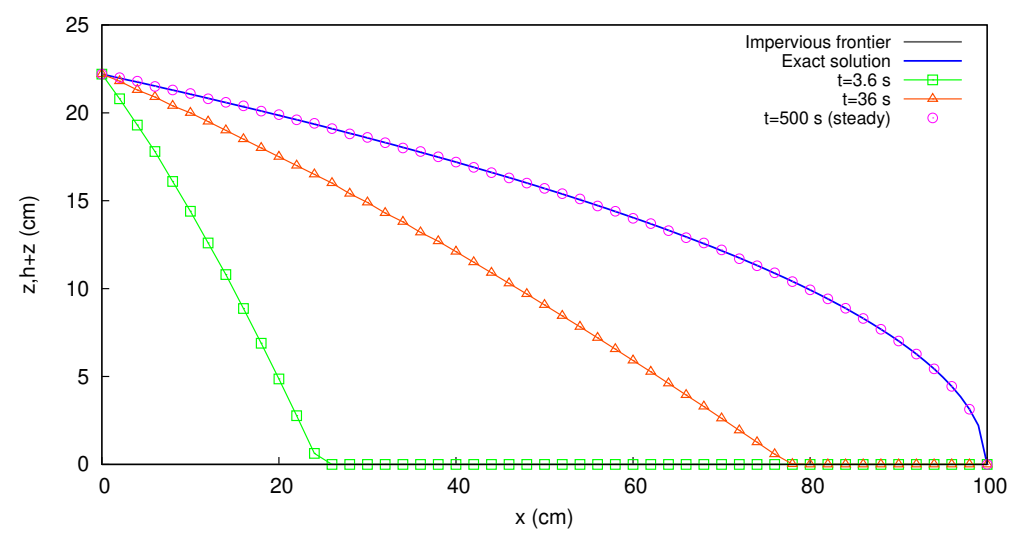

Figure 11: Comparison with analytical solution for Setup 1 in 1D case.

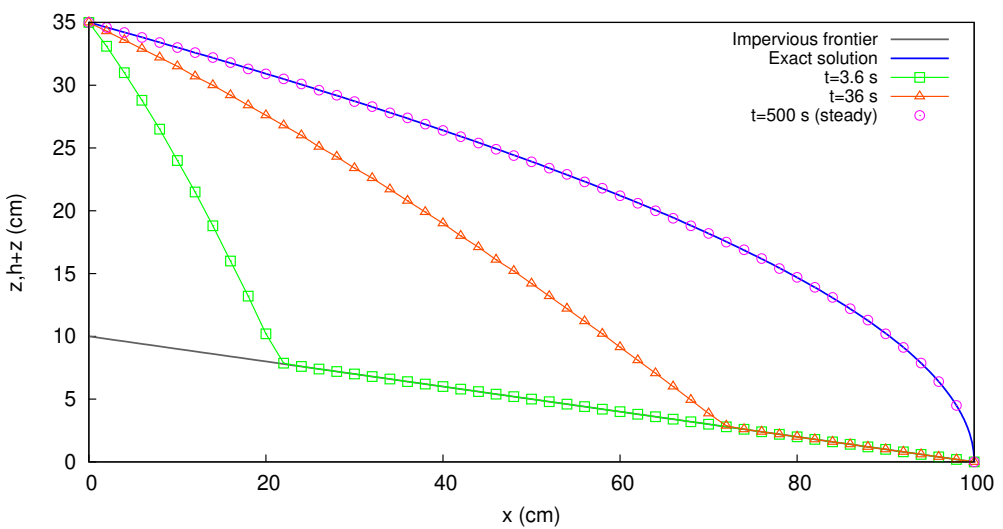

Figure 12: Comparison with analytical solution for Setup 2 in 1D case.

\subsection{Validation with laboratory data}

In this section, a validation with a sand tank laboratory test case is presented. This experiment simulates the wetting process through sand over a horizontal impervious stratum (13). The purpose of this case is to test the ability of the model to deal with a surface-groundwater flow in the presence of infiltration/exfiltration processes 53 . The dimensions of the tank were $1 \mathrm{~m}$ long, $0.55 \mathrm{~m}$ tall and the chamber was $3 \mathrm{~cm}$ wide (see Figure 13 ). The front and rear panels were built of $5 \mathrm{~mm}$ thick methacrylate sheets. The sides of the tank conformed its boundary conditions. A pneumatic cylinder to open and close a 
gate was placed at the left boundary in order to set a fixed inlet water level. An elevated water tank was connected by a hose to the inlet side of the sand tank. The water tank allowed to keep a constant pressure water supply to the sand tank. On the other hand, free outflow conditions were considered at the right boundary. Six differential piezometers were placed at the bottom of the sand tank at $x=15 \mathrm{~cm}, 30 \mathrm{~cm}, 45 \mathrm{~cm}, 55 \mathrm{~cm}, 70 \mathrm{~cm}$ and $85 \mathrm{~cm}$ for the experimental measuring of the hydraulic head.

The initial condition was dry sand, placed to form two slopes (-20.8\% and $70 \%$ ) with slope angles significantly lower than the natural angle of repose of the soil, in order to avoid high velocities and erosion. The hydraulic conductivity of the considered sand is $K_{s}=0.51 \mathrm{~cm} / \mathrm{s}$ whereas the porosity was found to be $\eta=0.30$. An inlet water level of $15 \mathrm{~cm}$ was set at the left boundary so that a groundwater wetting front advanced eventually generating exfiltration when meeting the soil surface interface.

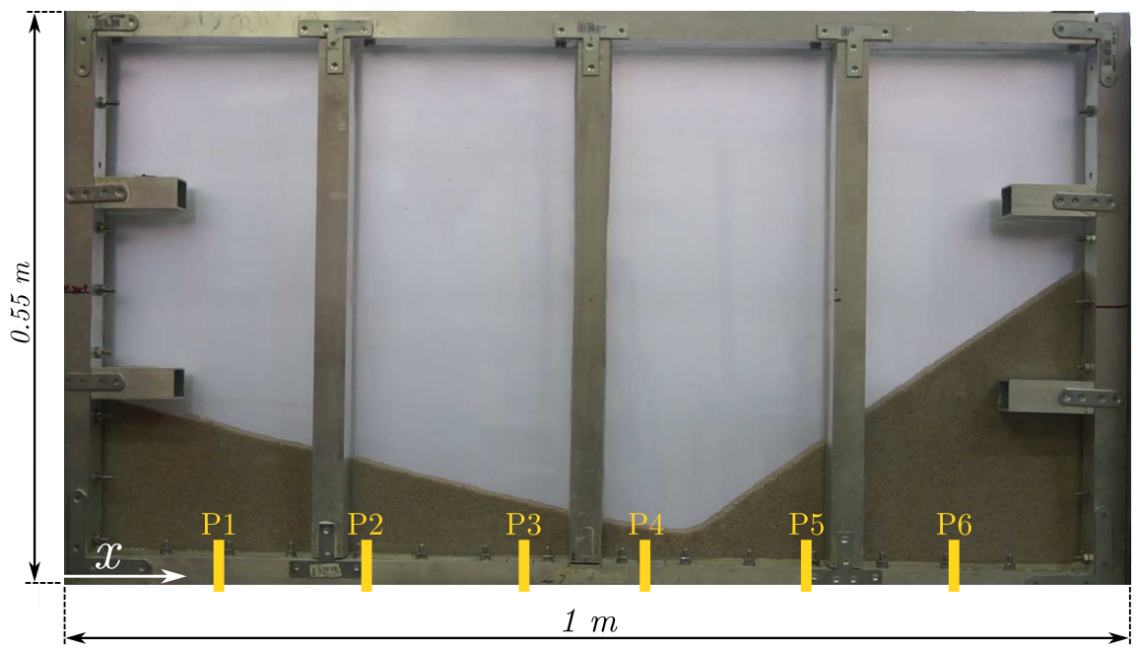

Figure 13: Sand tank front view, sand geometry and piezometer locations.

Figure 14 shows the numerical results for the free surface and phreatic water level at $t=200 \mathrm{~s}$ together with the piezometer measurings. A general good agreement between numerical and experimental data is observed in this situation in which exfiltration has taken place. The minimum differences $(3 \mathrm{~mm})$ are found 
in the fourth piezometer whereas a maximum difference of $1.5 \mathrm{~cm}$ is observed 450 at $x=0.85 \mathrm{~m}$. This differences fall within the error range of the piezometric devices.

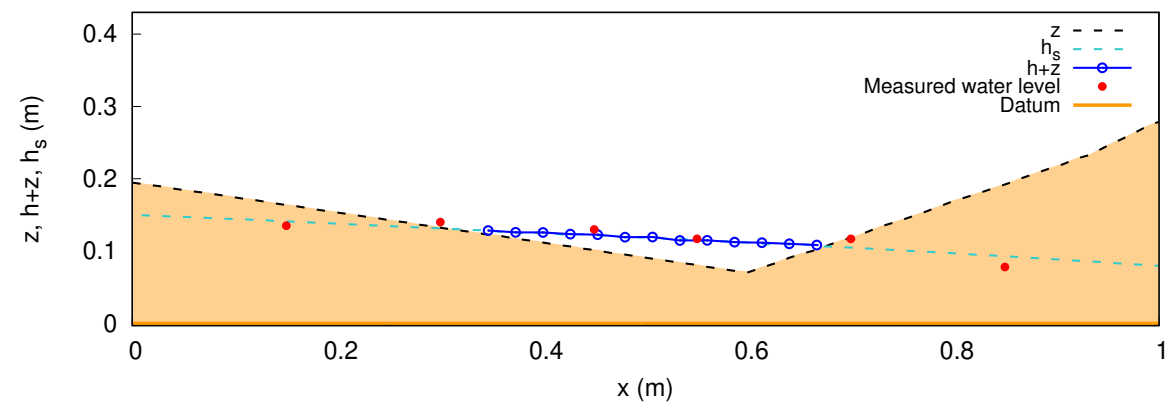

Figure 14: Numerical results and experimental measurings for the sand tank experiment. 


\section{Catchments description, meshing and mapping}

In this article, data from two sub-Mediterranean experimental mountain catchments, Arnás and Araguás, are used. Both basins have been widely studthe IPE/CSIC [16, 17]. Regarding the Arnás catchment, an exhaustive experimental study of the streamflow response, water-table dynamics and bed load transport was reported in [16, 17. The relationship among catchment soil moisture, rainfall characteristics and suspended sediments was assessed in [54, while ern Spanish Pyrenees, in the Borau valley. A 3D representation of the catchment together with the hypsometry map is shown in Figure 15 (upper, left). The 22624 cells mesh used for simulating all the cases presented in this paper is shown in Figure 15 (upper, right). The roughness map for this catchment is 480

the catchment soil erosion was experimentally studied in [55] and more recently in [56]. Another relevant aspect of this basin is the influence of the long term changes in land cover over the streamflow generation [57. The experimental study of the runoff generation and sediment transport in the Araguás catchment have been covered in the literature in the recent years [58, 59, 60]. A full assessment of the relationships among rainfall, runoff, and suspended sediment delivery is developed in [60 also for this basin. In addition, both catchments have been compared to each other in terms of their geomorphological characteristics, despite their geographical proximity [61, 62]. All the cited studies conclude that infiltration plays an important role in all the aspects of the catchment response due to the large precipitation losses. Regarding the sediment transport, Araguás catchment generates higher sediment concentration peaks than Arnás basin (up to 50 times higher for similar storm events) [61] and the grain size is lower than $0.5 \mathrm{~mm}$ for the event considered in this work 60.

\subsection{Arnás catchment}

The Arnás catchment (2.84 $\mathrm{Km}^{2}, 900-1340$ m.a.s.l.) is located in the Northshown in Figure 15 (lower). 


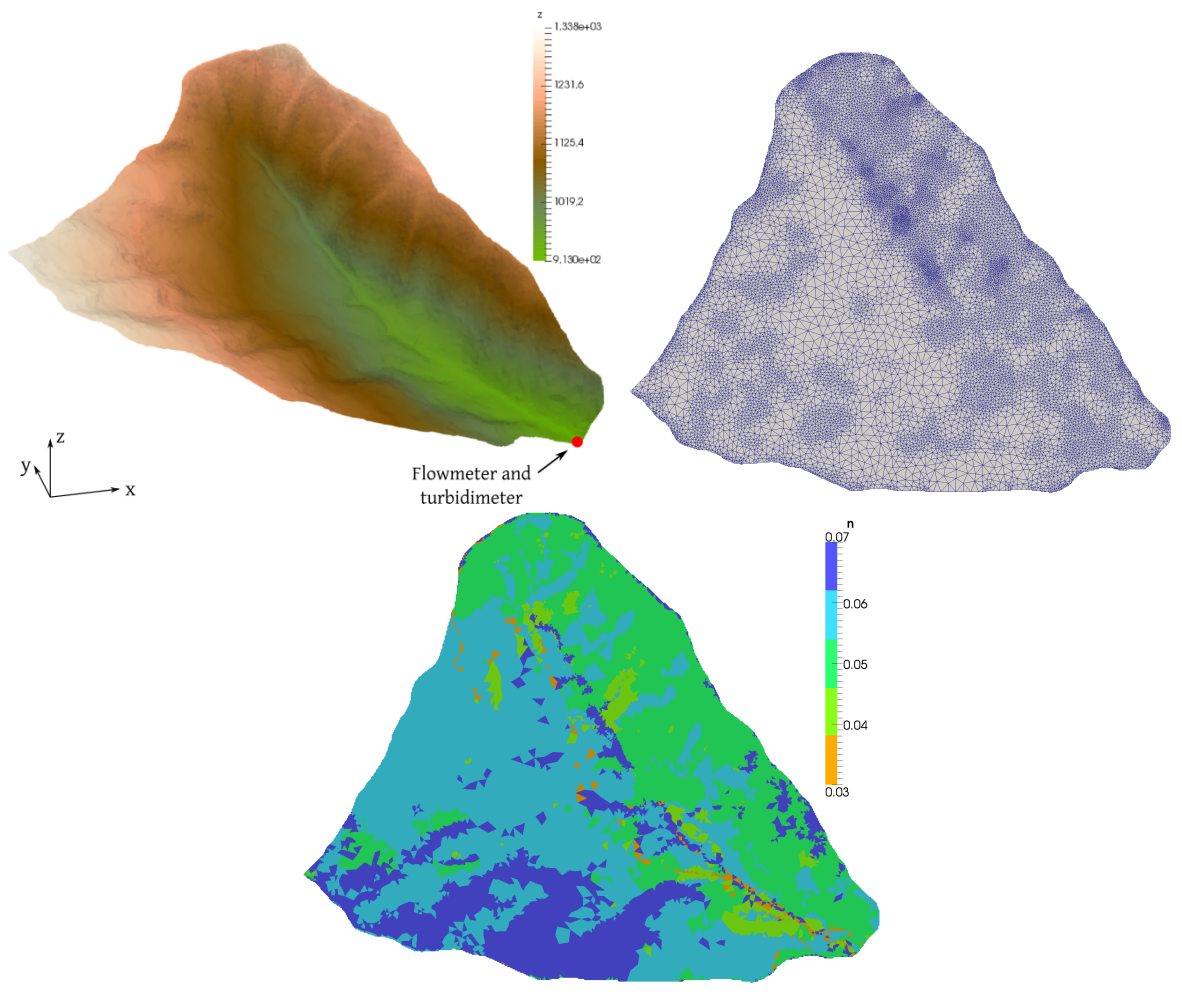

Figure 15: Arnás catchment hypsometry map, mesh characteristics and roughness map. 


\subsection{Araguás catchment}

The Araguás catchment is located in the Central Pyrenees (Figure 16, left) and it has an extension of $0.45 \mathrm{Km}^{2}$ [62. Its altitude ranges from 780 to 1100 m.a.s.l. and the mean slope varies from $20 \%$ to $43 \%$. Due to the small size of the basin, a constant Manning's roughness coefficient of $n=0.015 \mathrm{sm}^{-1 / 3}$ is set. A triangular unstructured mesh of 7728 cells is used for the spatial discretization of the catchment (Figure 16, right).

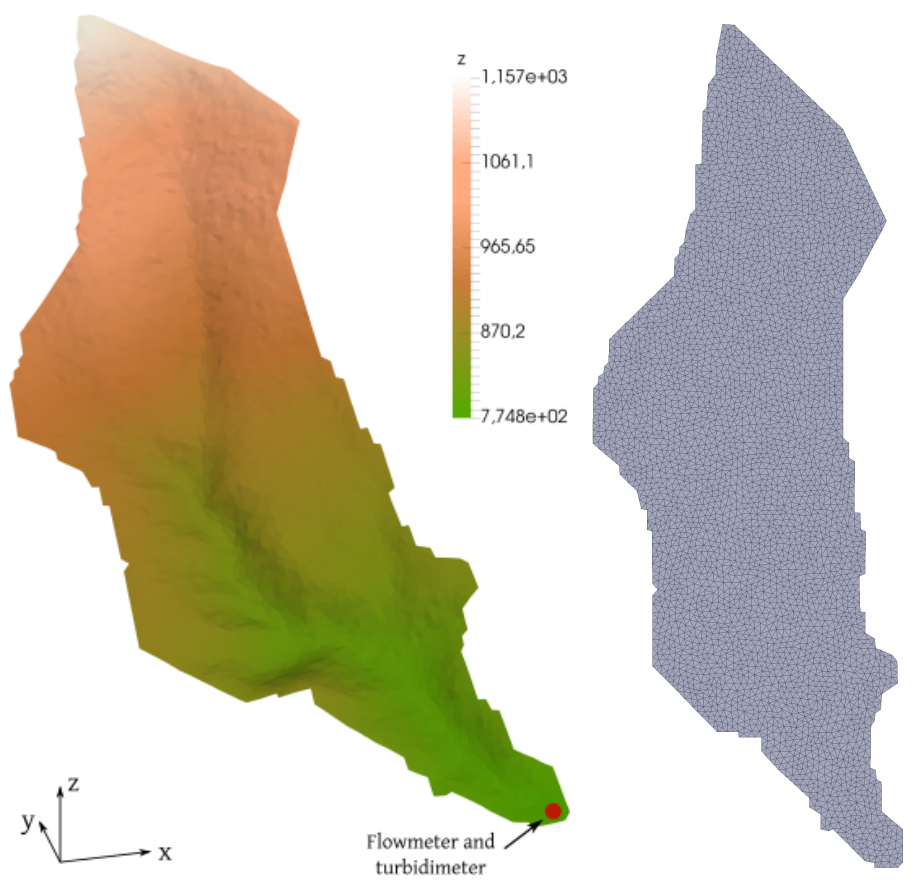

Figure 16: Araguás catchment characteristics. 


\section{Numerical results}

\subsection{Arnás catchment: Long-term hydrological simulation}

A long duration event (30 days) is considered as a first test case in the Arnás basin. Several storm events of different rain intensity occured within that period. The outlet discharge was continuously monitorized at the gauge depicted in Figure 15. The catchment infiltration rate is computed by means of the SCS-CN model with $C N=19$ and $\sigma=0.02$. The groundwater flow is not considered in this test. Figure 17 shows the measured hyetograph for this event and the observed peak discharge values, together with numerical outlet hydrograph. It is important to note that only peak discharge values were provided. The main purpose of this test is to point out that even the simplest infiltration model can provide good results when the storm event is very long. After a short period of adaptation with transient conditions at the soil-surface interface, all the outlet discharge peak are well reproduced in terms of peak values and arrival time. Several repetitions of the full simulation have been necessary in order to adjust the parameters of the infiltration model. It is worth mentioning that the calculation time for this 30 days simulation has been approximately $3700 \mathrm{~s}$. The ability to perform simulations in such an agile way greatly facilitates the calibration process.

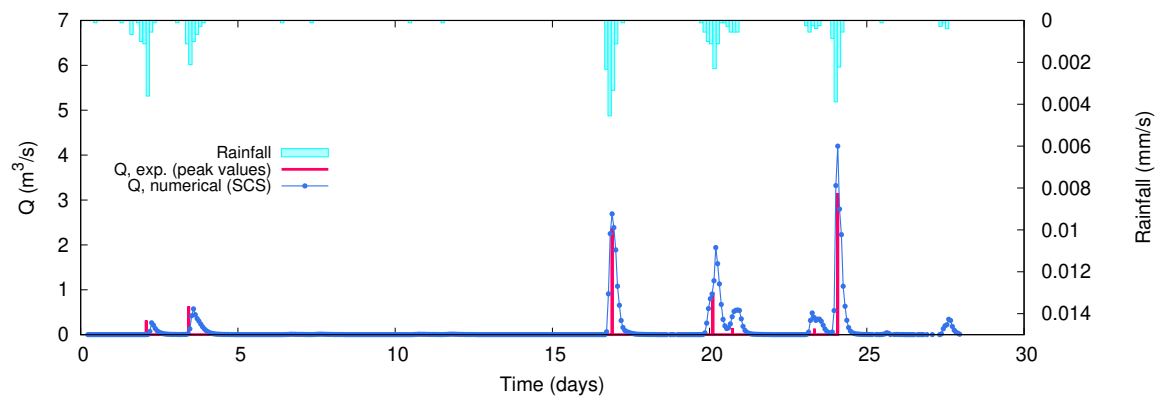

Figure 17: Arnás catchment long-term hydrological simulation: Outlet numerical hydrograph and comparison against experimental data for a 30 days event. 


\subsection{Arnás catchment: Groundwater flow model time step optimization}

In this section, the coupled overland-groundwater flow model is applied to the Arnás basin, assuming a synthetic case, where a progressive raising of the phreatic level is assumed at two points of the basin boundary. In the absence of field data, the purpose is to develop a performance analysis in terms of the computational cost with several time step values for the groundwater flow model. Therefore the sensitivity of the coupled model to the communication frequency can be evaluated. Additionally it will allow to check the capacity of the coupled model to route this change through the subsurface and generate a streamflow response due to exfiltration in the main channel of the catchment. The impervious stratum is assumed to be far below so that it has little or no influence. The properties of the porous media are $K_{s}=0.15 \mathrm{~cm} / \mathrm{s}$ and $\eta=0.3$.

Figure 18 shows the evolution of the phreatic level and surface water depth at several times. The smooth progression of two groundwater flows can be observed. They eventually meet and exfiltration begins at $t=4750 \mathrm{~s}$. Table 2 and Figure 19 shows, for several choices of the groundwater flow model time step, the CPU time and the speed-up factor Speed $-u p=\frac{\operatorname{CPUtime}\left(N_{\text {sup }}=1\right)}{\operatorname{CPUtime}\left(N_{\text {sup }}\right)}$, being $N_{\text {sup }}$ the number of surface model time steps for one single subsurface model time step. The maximum and average errors in the water table elevation relative to a simulation performed with $N_{\text {sup }}=1$ are also shown. In the light of this analysis, acceptable simulations with average errors below $2 \%$ can be reached using subsurface time steps 25 times larger than the surface flow model. With this choice, a speed-up value of 8 is reached. As the implicit numerical scheme does not restrict the time step size and the groundwater flow is expected to be much slower than the overland flow, it is shown that larger time steps provide faster simulations. This particular case represents an uninteresting situation from a hydrological perspective due to the unrealistic hydraulic conductivity chosen. If the value was reduced to more realistic values, the groundwater flow would be slower, hence requiring even less frequency of communication with the surface flow. 


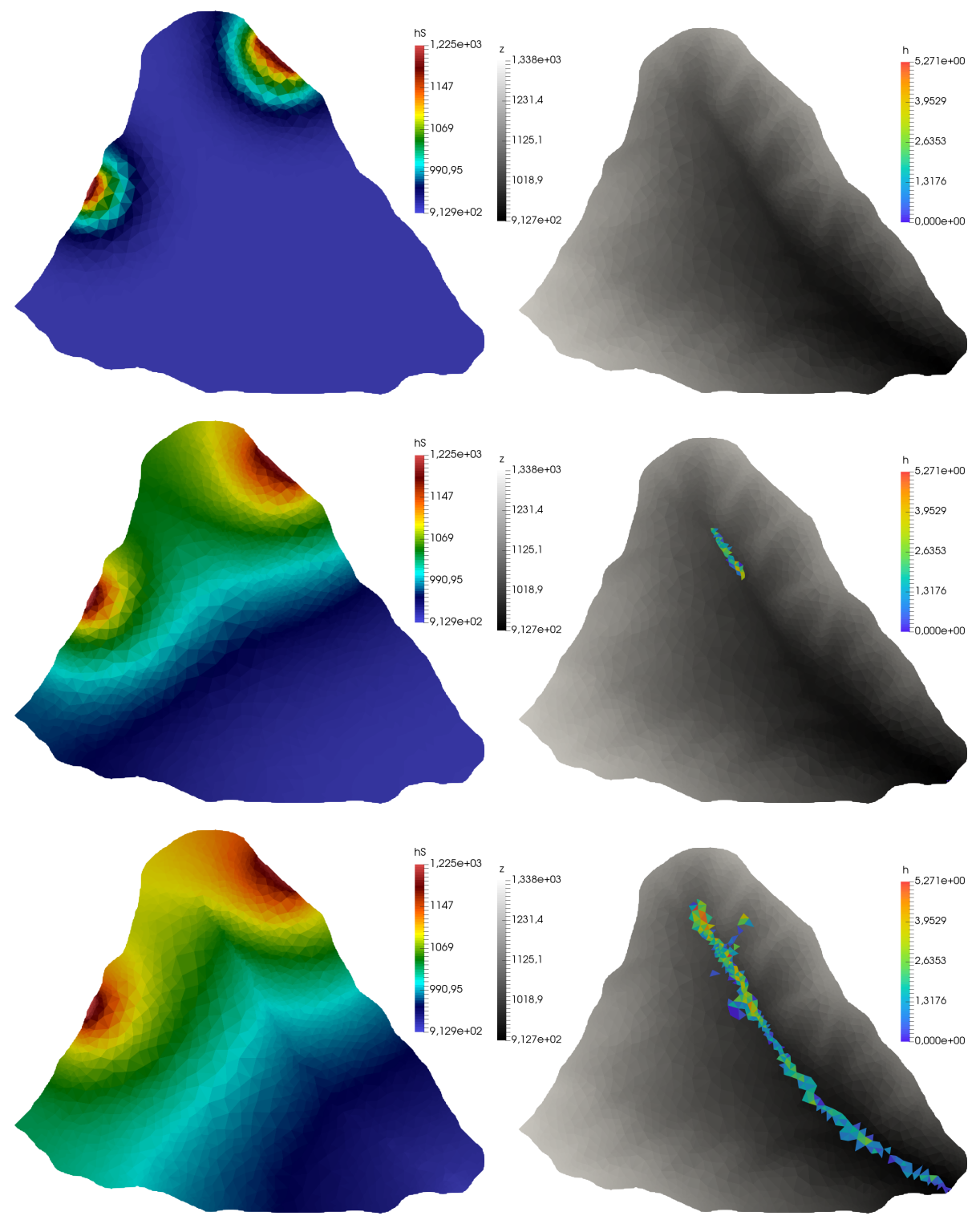

Figure 18: Groundwater flow model time step optimization: Subsurface phreatic level position $h_{s}$ (left) and surface water depth $h$ at $t=500 \mathrm{~s}$ (upper), $t=4750 \mathrm{~s}$ (middle) and $t=10000 \mathrm{~s}$ (lower). 


\begin{tabular}{lllll}
$N_{\text {sup }}$ & CPU time & Speed-up & Maximum error (\%) & Water table average error $(\%)$ \\
\hline 1 & 125 & 1 & 0 & 0 \\
2 & 71.5 & 1.7 & 0.29 & 0.01 \\
3 & 49.7 & 2.5 & 0.43 & 0.02 \\
10 & 22.15 & 5.6 & 0.82 & 0.08 \\
17 & 19.6 & 6.4 & 0.97 & 0.14 \\
25 & 15.6 & 8.0 & 1.22 & 0.18 \\
\hline
\end{tabular}

Table 2: Groundwater flow model time step optimization: CPU time, speed-up and maximum and water table average errors. 

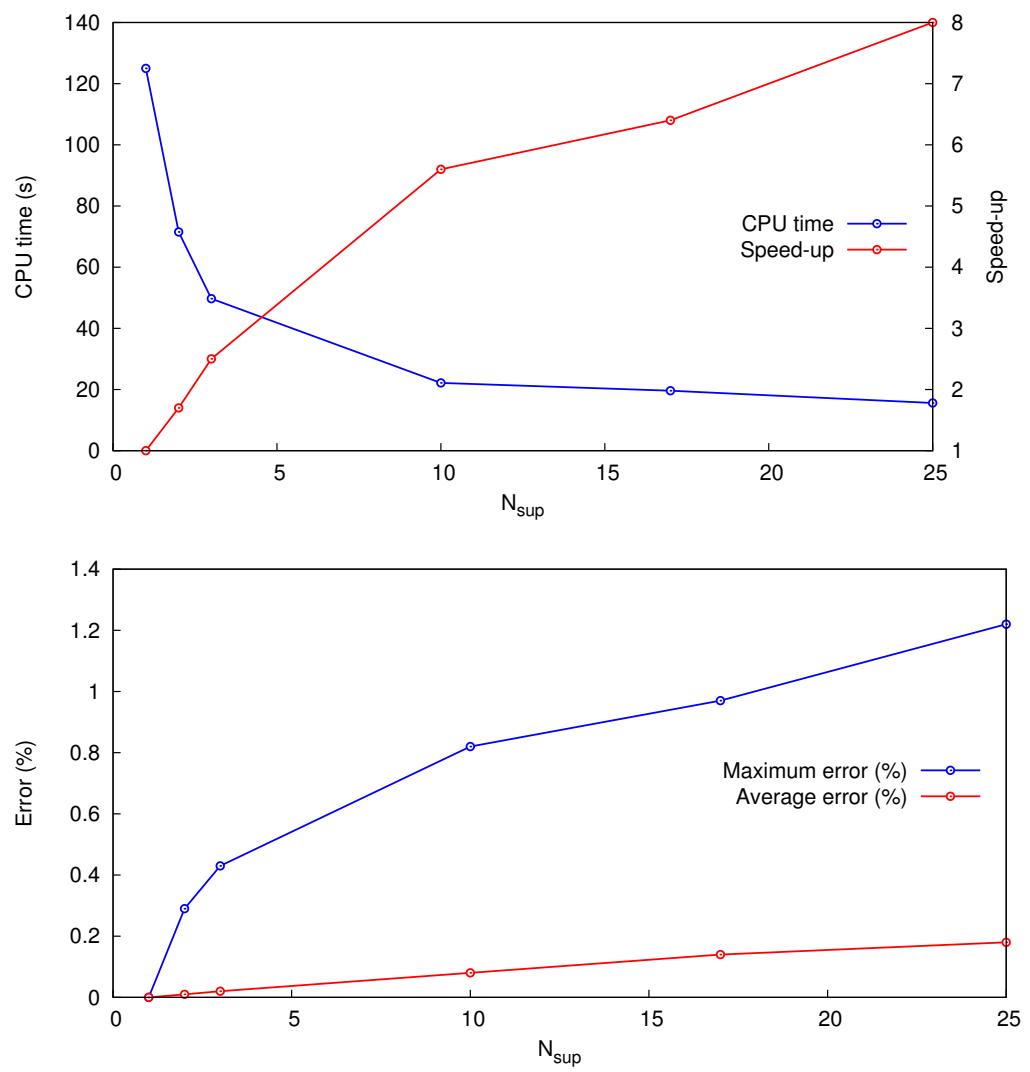

Figure 19: Groundwater flow model time step optimization: CPU time and speed-up values (left). Maximum and average error values all along the spatial domain at final simulation time $(t=10000 s)$ (right).

\subsection{Arnás catchment: Hydrological response}

A short duration single rainfall event is studied and compared with the field measured data. Flow and sediment measurements were acquired at the outlet on the Arnás ravine (see Fig. 15) with 5 minutes frequency. Rainfall was registered by a rain gauge with a frequency of 5 minutes. Figure 20 shows the rainfall hyetograph and the measured outlet hydrograph for the considered storm event.

The hypothesis for the initial phreatic surface is based in several factors.

First, the measurements at a few water table gauges provided in [16] for this 


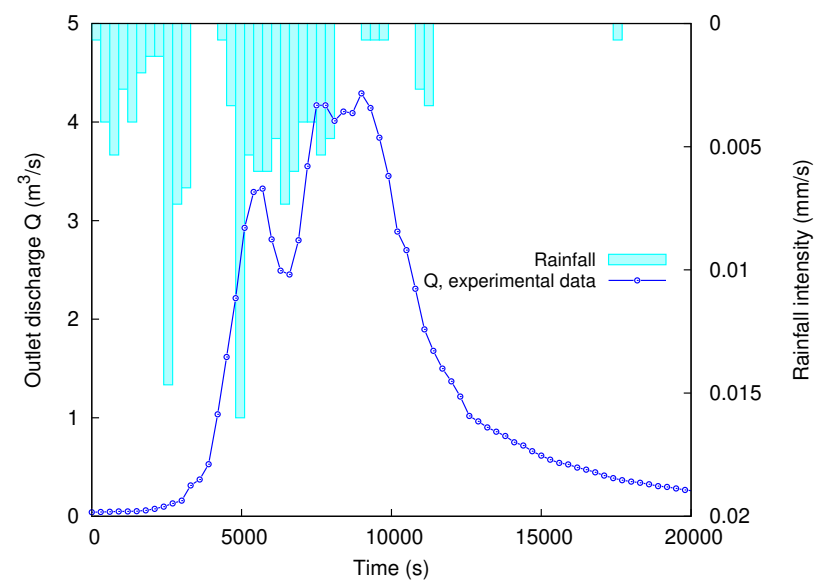

Figure 20: Arnás catchment hydrological response: Experimental hyetograph for Arnás basin.

particular event have been taking into account. Additionally, some area near the catchment outlet was initially ponded, so the phreatic surface has been forced to join the surface water level in that zone. All this information has been interpolated with the following equation for the initial water table surface:

$$
h_{s}(x, y)=h_{s}^{\min }+C\left(z_{b}(x, y)-h_{s}^{\min }\right)
$$

550

$$
\text { ing }
$$

initial phreatic surfaces have been considered depending on the value of the parameter $C$ : PL01 $(C=0.62)$, PL02 $(C=0.61)$ and PL03 $(C=0.63)$. Figure 21 shows the graphical representation of the initial phreatic surface for PL01 setup. Regarding the parameters for the groundflow model, a saturated hydraulic conductivity $K_{s}=1.9 \cdot 10^{-6} \mathrm{~m} / \mathrm{s}$ and a porosity $\eta=0.56$ are considered for all the cases presented in this section.

Regarding the infiltration parameters of the FOGA model, the same parameter set as in [6] has been kept $\left(K_{\alpha}=1.8 \cdot 10^{-6} \mathrm{~m}^{\alpha} / \mathrm{s}, \Psi=0.01 \mathrm{~m}, \Delta \theta=\right.$ ${ }_{560} 3.5 \mathrm{~m}^{3} / \mathrm{m}^{3}$ ), except for the hydraulic conductivity which will be slightly modified in order to improve the outlet hydrograph fitting. 


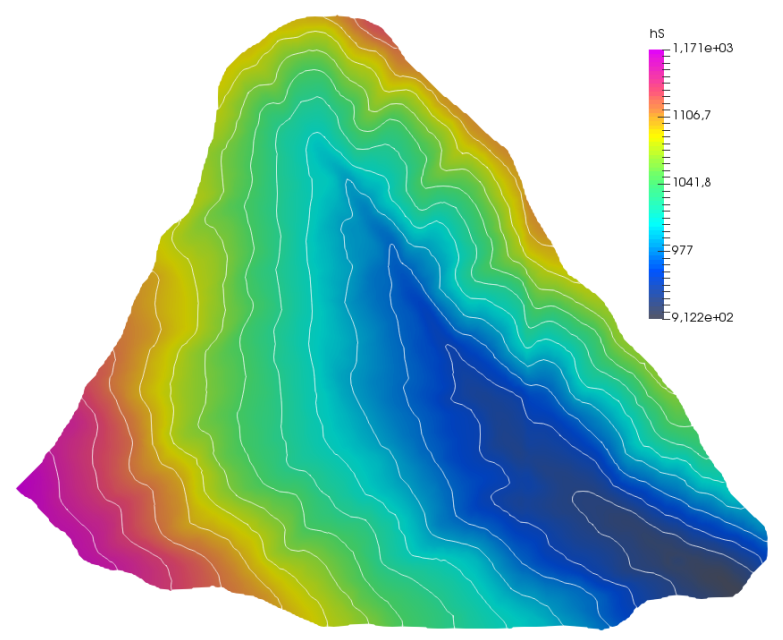

Figure 21: Initial assumption for the Arnás catchment phreatic surface (PL01). Contour lines correspond to $h_{s}$.

Figure 22 shows the numerical outlet hydrographs obtained with (blue line) and without (red line) taking into consideration the groundwater flow model, as well as the comparison with the observed data. An increase in the outlet discharge due to the additional contribution of exfiltration can be seen. In order to improve the fitting, the hydraulic conductivity is raised to $K_{\alpha}=1.9$. $10^{-6} \mathrm{~m}^{\alpha} / \mathrm{s}$, obtaining the hydrograph presented in Figure 23 where a better fit of the last part of the falling limb is achieved. Figure 24 illustrates the surface flow and the phreatic values for two different simulation times. This is useful 570 to justify the initial existence of surface water at certain locations. 


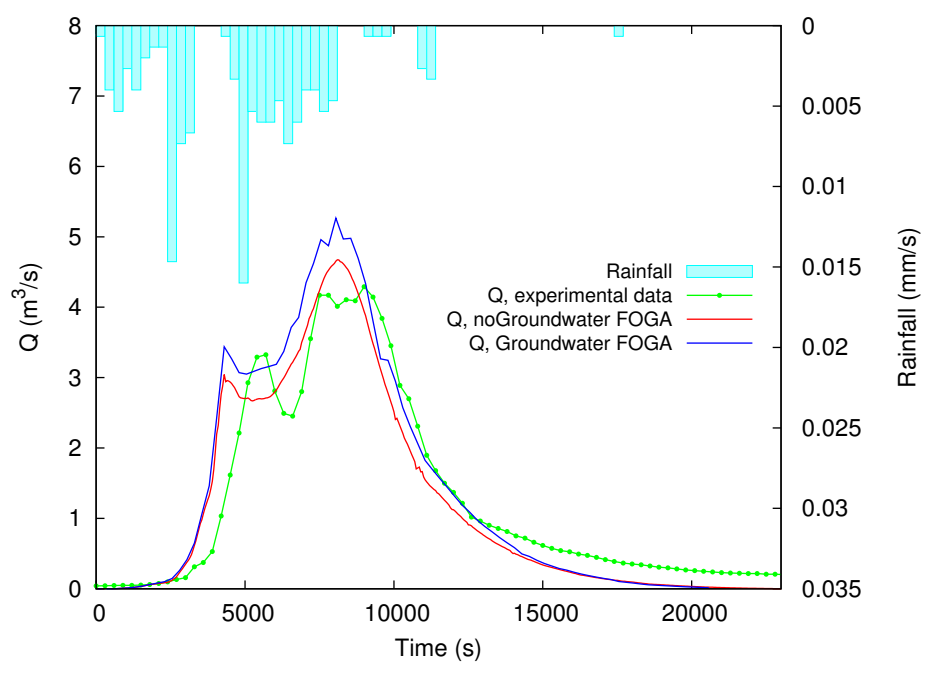

Figure 22: Arnás catchment hydrological response: Original FOGA outlet hydrograph vs. PL01 with $K_{\alpha}=1.8 \cdot 10^{-6} \mathrm{~m}^{\alpha} / \mathrm{s}$.

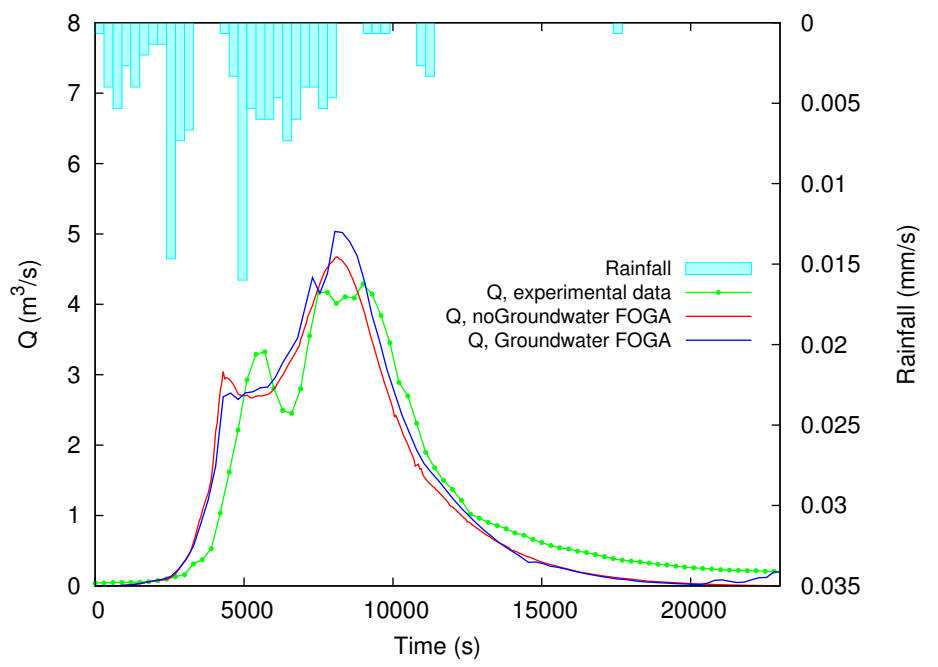

Figure 23: Arnás catchment hydrological response: Original FOGA outlet hydrograph vs. PL01 with $K_{\alpha}=1.9 \cdot 10^{-6} \mathrm{~m}^{\alpha} / \mathrm{s}$. 

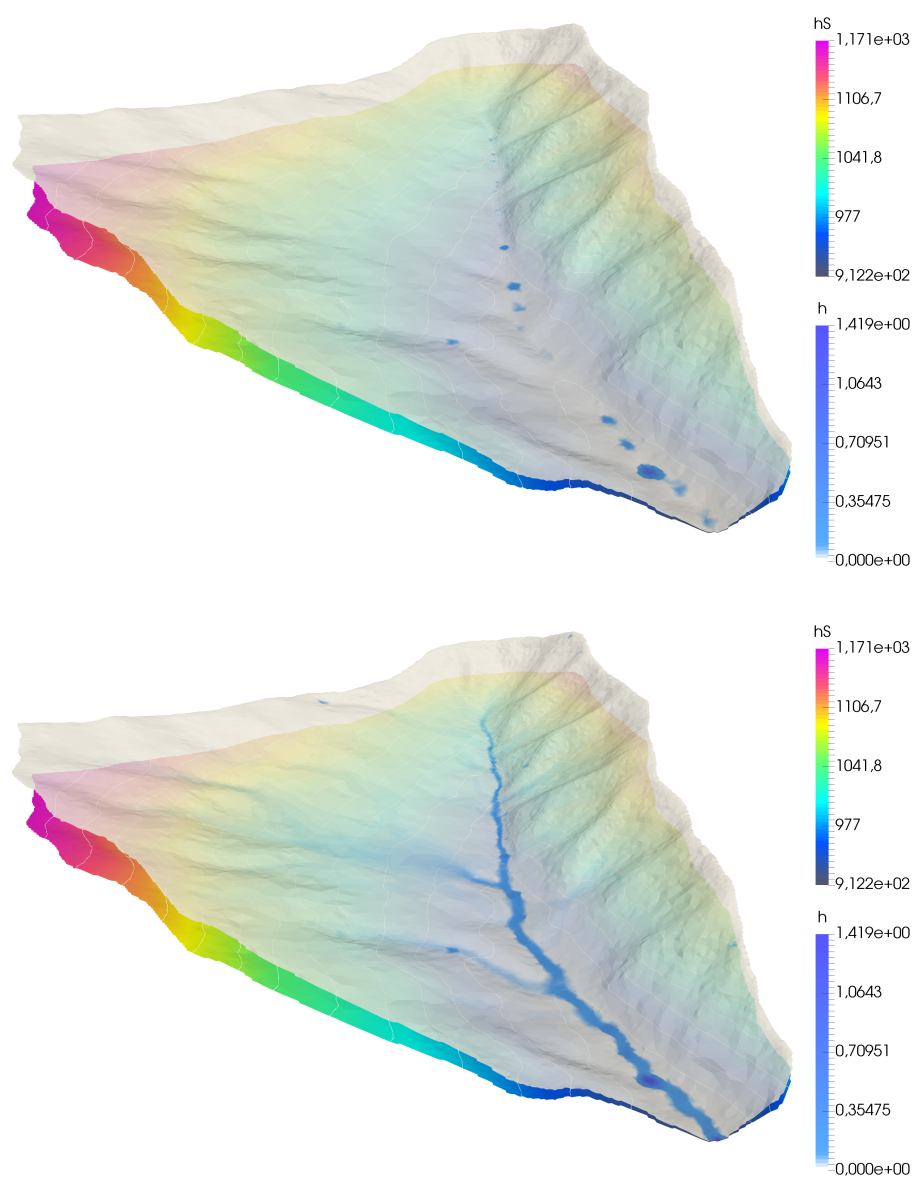

Figure 24: Arnás catchment hydrological response: 3D view of the overland flow and phreatic surface for $t=0$ (upper) and $t=9000 \mathrm{~s}$ (lower) with PL01. 
In order to test the sensitivity to the initial phreatic surface position, two additional setups are considered (PL02 and PL03). Figure 25 shows the comparison among initial phreatic levels. The huge sensitivity of the last part of the hydrograph to this initial condition should be emphasized, specially remarkable 575 for PL03 where an excesive exfiltration occurs. Table 3 shows the error quantification for this case, in term of the Root Mean Square Error (RMSE) for the whole simulation and for the falling limb of the hydrograph $\left(R M S E_{t>12000 s}\right)$ :

$$
R M S E=\sqrt{\frac{\sum\left(Q-Q_{\text {observed }}\right)^{2}}{N_{\text {obs }}}}
$$

being $Q_{\text {observed }}$ the values of the $N_{\text {obs }}$ measured discharge values. The maximum error values are also shown, computed as

$$
\text { Error } \max =\max \left\{Q-Q_{\text {observed }}\right\}
$$

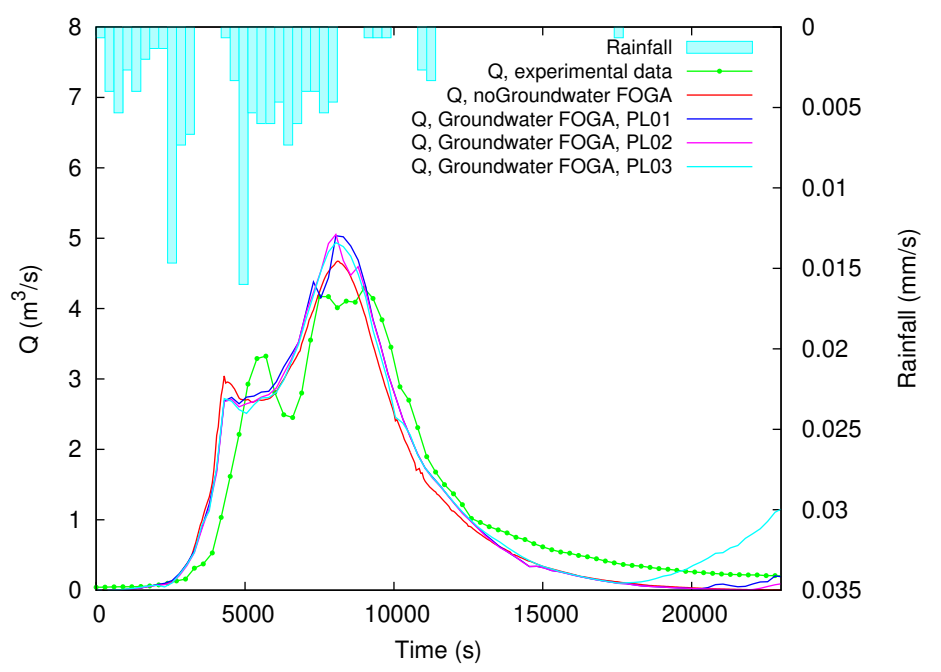

Figure 25: Arnás catchment hydrological response: Comparison among initial phreatic levels. 


\begin{tabular}{lllll} 
Setup & $K_{\alpha}\left(m^{\alpha} / s\right)$ & $R M S E$ & $R M S E_{t>12000 s}$ & Error $_{\max }$ \\
\hline FOGA & $1.8 \cdot 10^{-6}$ & 0.415 & 0.168 & 1.73 \\
FOGA+PL01 & $1.8 \cdot 10^{-6}$ & 0.576 & 0.343 & 2.09 \\
FOGA+PL01 & $1.9 \cdot 10^{-6}$ & 0.391 & 0.163 & 1.32 \\
FOGA+PL02 & $1.8 \cdot 10^{-6}$ & 0.385 & 0.167 & 1.30 \\
FOGA+PL03 & $1.8 \cdot 10^{-6}$ & 0.992 & 0.930 & 3.48 \\
\hline
\end{tabular}

Table 3: Arnás catchment hydrological response: RMSEs and maximum errors for all the case setups.

\subsection{Arnás catchment: Sediment transport}

In this section, the numerical results corresponding to the sediment transport in the Arnás basin are shown. Following the guidelines presented in [17, 61, both suspended and bed load sediment transport are considered. The observed hydrograph and sedigraph is shown in Figure 26. In order to understand how the parameters of the sediment model affect the numerical sedigraphs, a full sensitivity analysis is developed in this section considering variations in sediment porosity $p$, density $\rho$ and grain diameter $d_{50}$. The diameters $d_{30}$ and $d_{90}$ mantain the proportion of the values assumed as reference $\left(d_{30}=0.6 \mathrm{~mm}\right.$ and $d_{90}=$ $50 \mathrm{~mm})$. The influence of the soil roughness map is also studied by modifying the original friction map (Figure 15) by a constant factor FR as follows:

$$
n^{\prime}=n+F R n
$$




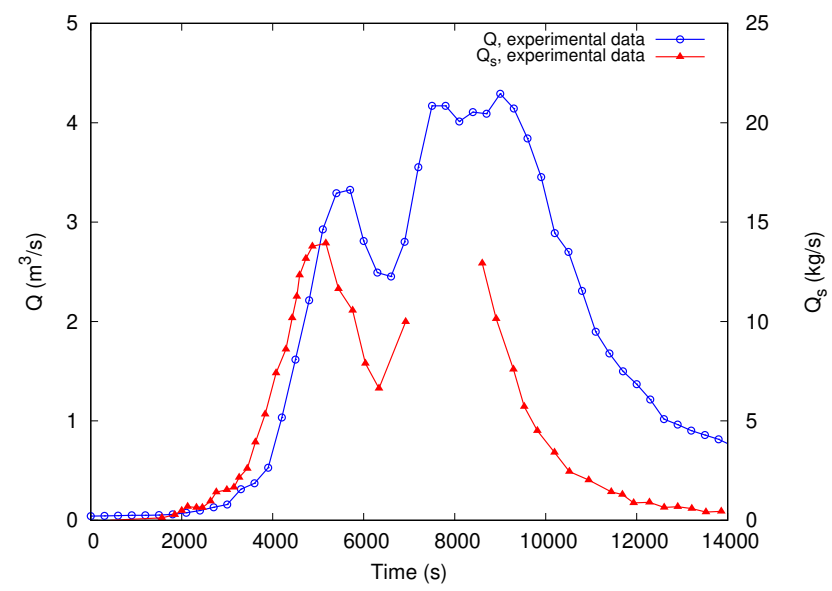

Figure 26: Arnás catchment sediment transport: Experimental sedigraph for Arnás basin.

A set of 25 simulations are presented below (see Table 4). Figure 27 shows the outlet hydrograph (upper) and sedigraph (lower) for friction sensitivity analysis. Only 3 of the 7 friction maps are shown, for the sake of clarity. In can be seen how both the water and solid discharges are significantly modified by the roughness values. This is specially noticeable for the second solid peak discharge. The sediment porosity (Figure 28) does not affect at all the water discharge. Nevertheless, there is an inverse relationship between the porosity and the solid discharge for the peak values. Regarding the density sensitivity analysis, a very good fit to the observed sedigraph is achieved when setting a value of $\rho=2000 \mathrm{~kg} / \mathrm{m}^{3}$ (see Figure 29. This agrees with the measured density values 63 for this particular region and period of time. Finally, the solid discharge is found to be inversely proportional to the grain diameter (Figure 30). In all cases, the error values for outlet water and solid volume are also presented as the relative difference between the numerical and observed values (Figure 31. It is clear that setup D2 provides the minimum error $(0.37 \%)$ in the sedigraph fit reaching also the minimum value $(6.68 \%)$ for the combined error (average between water and sediment error fit).

Figure 32 shows the best combined fit for numerical hydrograph and sedigraph. The results corresponding to the classical GA model are also depicted 
for both liquid and solid discharges. In the light of the numerical results, several conclusions can be drawn: 1) The GA infiltration model predicts excessive infiltration in the early period of the storm, leading to a wrong reproduction of the outlet hydrograph; 2) A wrong fit of the outlet hydrograph generates a wrong numerical outlet sedigraph. In other words, a correct estimation of the infiltration along the whole catchment is essential in order to carry out an adequate sediment transport computation. 3) The use of a more sophisticated infiltration law improves significantly both hydrograph and sedigraph fits. 


\begin{tabular}{|c|c|c|c|c|}
\hline Case & $\rho\left(k g / m^{3}\right)$ & $d_{50}(\mathrm{~mm})$ & $p$ & $F h$ \\
\hline FR1 & 2650 & 5 & 0.56 & 0 \\
\hline FR2 & 2650 & 5 & 0.56 & 0.2 \\
\hline FR3 & 2650 & 5 & 0.56 & 0.4 \\
\hline FR4 & 2650 & 5 & 0.56 & 0.6 \\
\hline FR5 & 2650 & 5 & 0.56 & 0.8 \\
\hline FR6 & 2650 & 5 & 0.56 & 1.0 \\
\hline FR7 & 2650 & 5 & 0.56 & 1.2 \\
\hline $\mathrm{P} 1$ & 2650 & 5 & 0.5 & 0.8 \\
\hline $\mathrm{P} 2$ & 2650 & 5 & 0.53 & 0.8 \\
\hline P3 & 2650 & 5 & 0.56 & 0.8 \\
\hline $\mathrm{P} 4$ & 2650 & 5 & 0.59 & 0.8 \\
\hline P5 & 2650 & 5 & 0.62 & 0.8 \\
\hline $\mathrm{P} 6$ & 2650 & 5 & 0.65 & 0.8 \\
\hline D1 & 1750 & 5 & 0.56 & 0.8 \\
\hline D2 & 2000 & 5 & 0.56 & 0.8 \\
\hline D3 & 2300 & 5 & 0.56 & 0.8 \\
\hline D4 & 2475 & 5 & 0.56 & 0.8 \\
\hline D5 & 2650 & 5 & 0.56 & 0.8 \\
\hline D6 & 2850 & 5 & 0.56 & 0.8 \\
\hline GS1 & 2650 & 4.7 & 0.56 & 0.8 \\
\hline GS2 & 2650 & 5 & 0.56 & 0.8 \\
\hline GS3 & 2650 & 5.3 & 0.56 & 0.8 \\
\hline GS4 & 2650 & 5.6 & 0.56 & 0.8 \\
\hline GS5 & 2650 & 5.9 & 0.56 & 0.8 \\
\hline GS6 & 2650 & 6.2 & 0.56 & 0.8 \\
\hline
\end{tabular}

Table 4: Set of cases for sediment transport sensitivity analysis in the Arnás basin. 

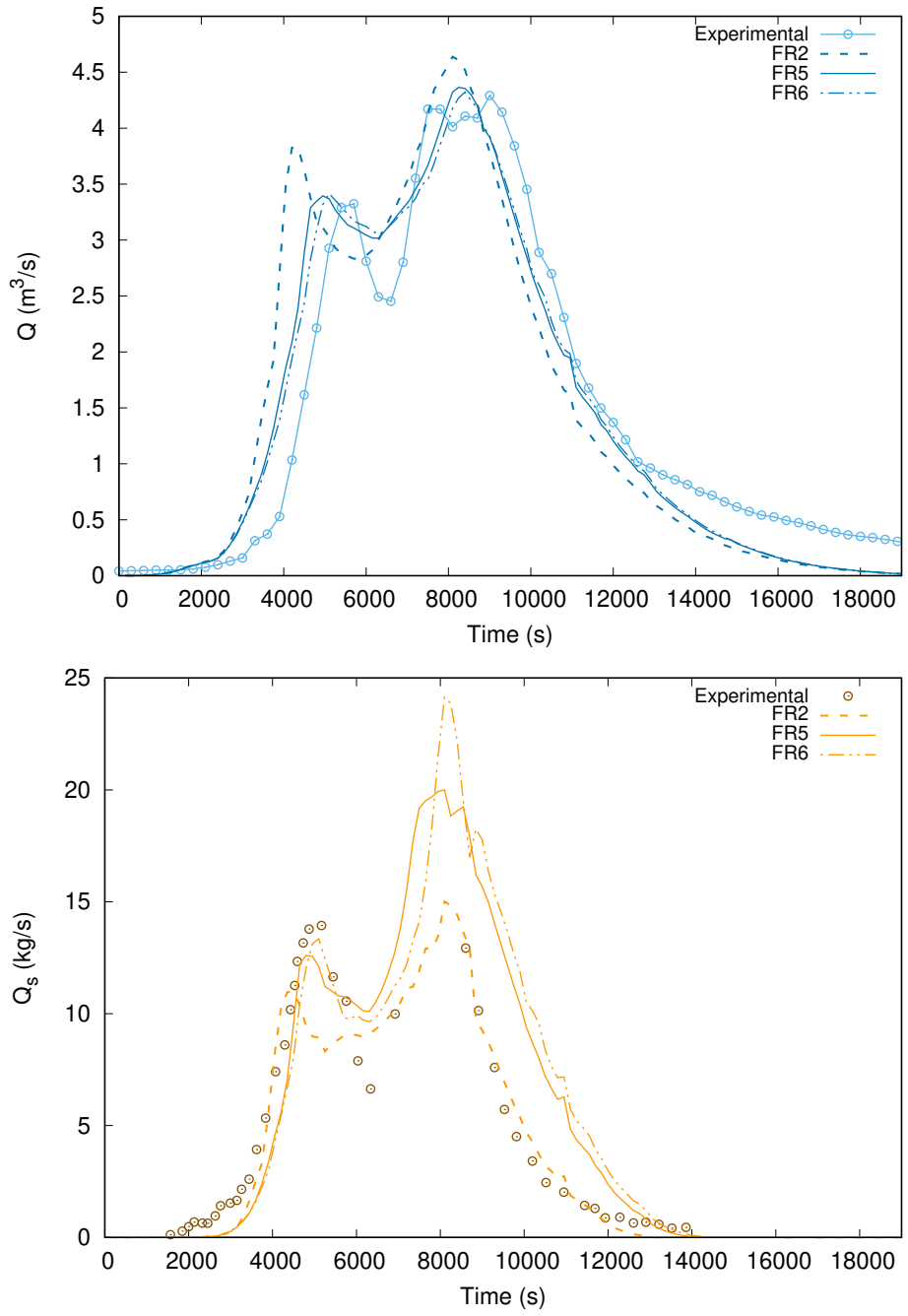

Figure 27: Arnás catchment sediment transport: Outlet hydrograph (upper) and sedigraph (lower) for friction sensitivity analysis. 

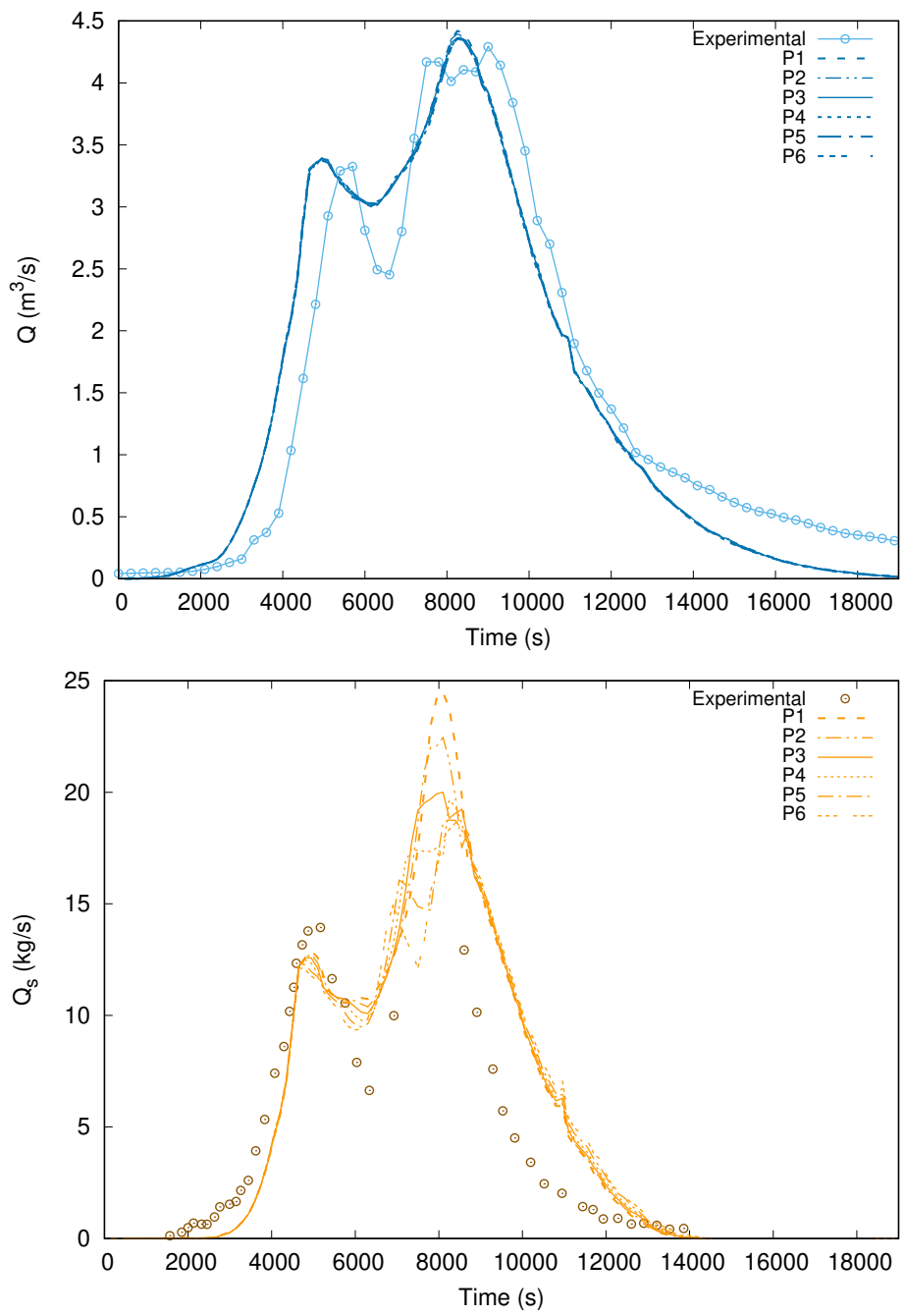

Figure 28: Arnás catchment sediment transport: Outlet hydrograph (upper) and sedigraph (lower) for porosity sensitivity analysis. 

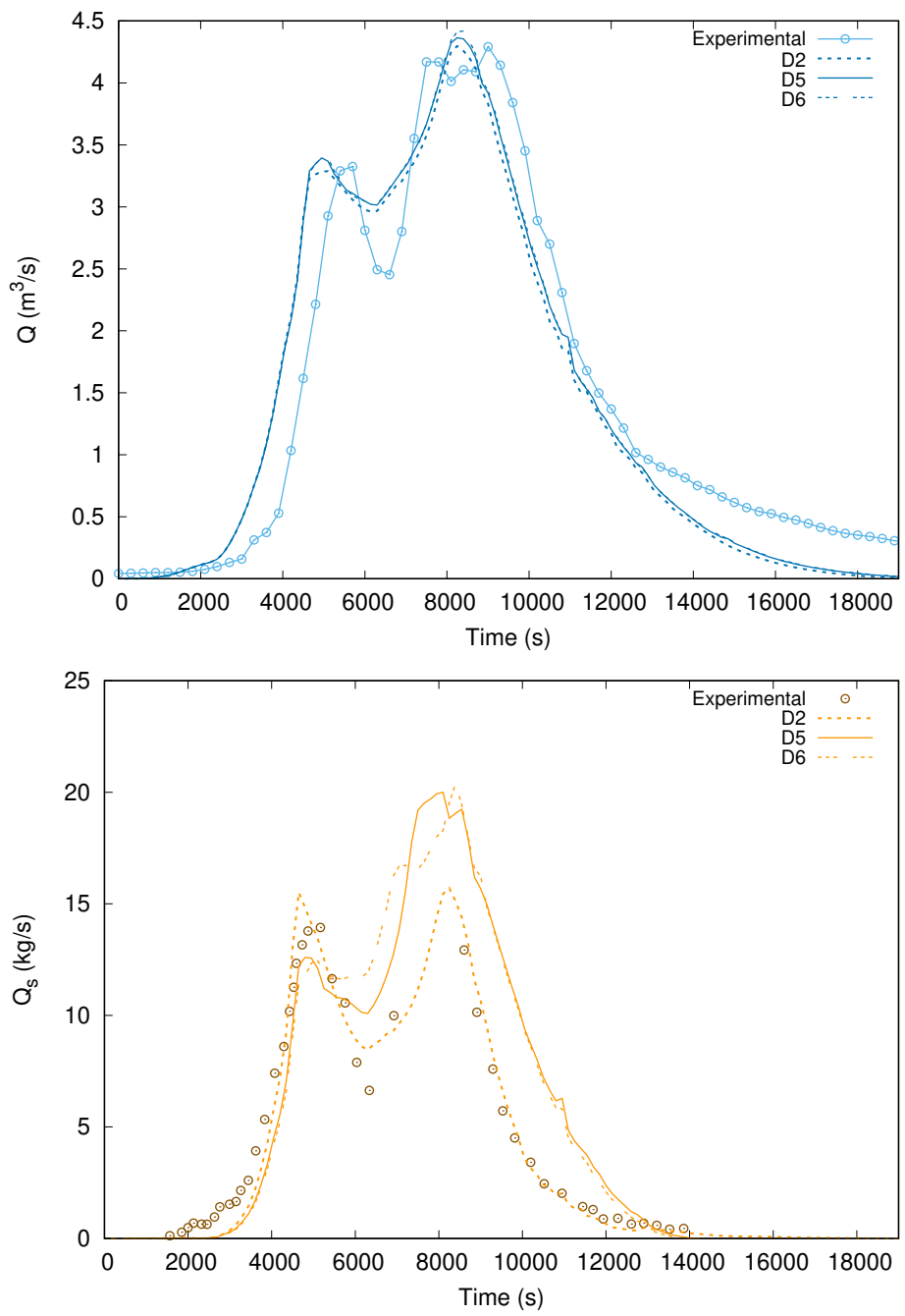

Figure 29: Arnás catchment sediment transport: Outlet hydrograph (upper) and sedigraph (lower) for sediment density sensitivity analysis. 

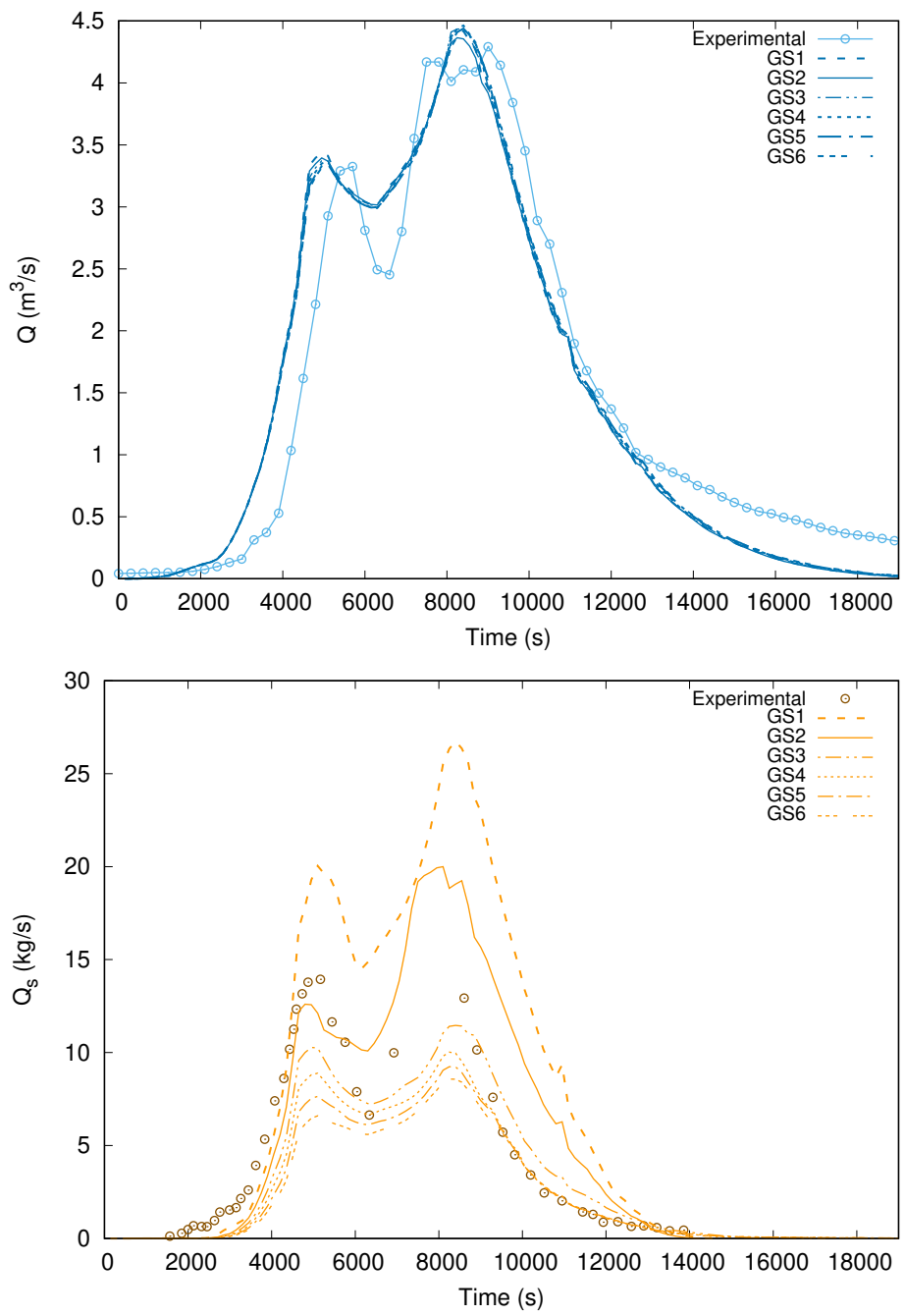

Figure 30: Arnás catchment sediment transport: Outlet hydrograph (upper) and sedigraph (lower) for grain size sensitivity analysis. 


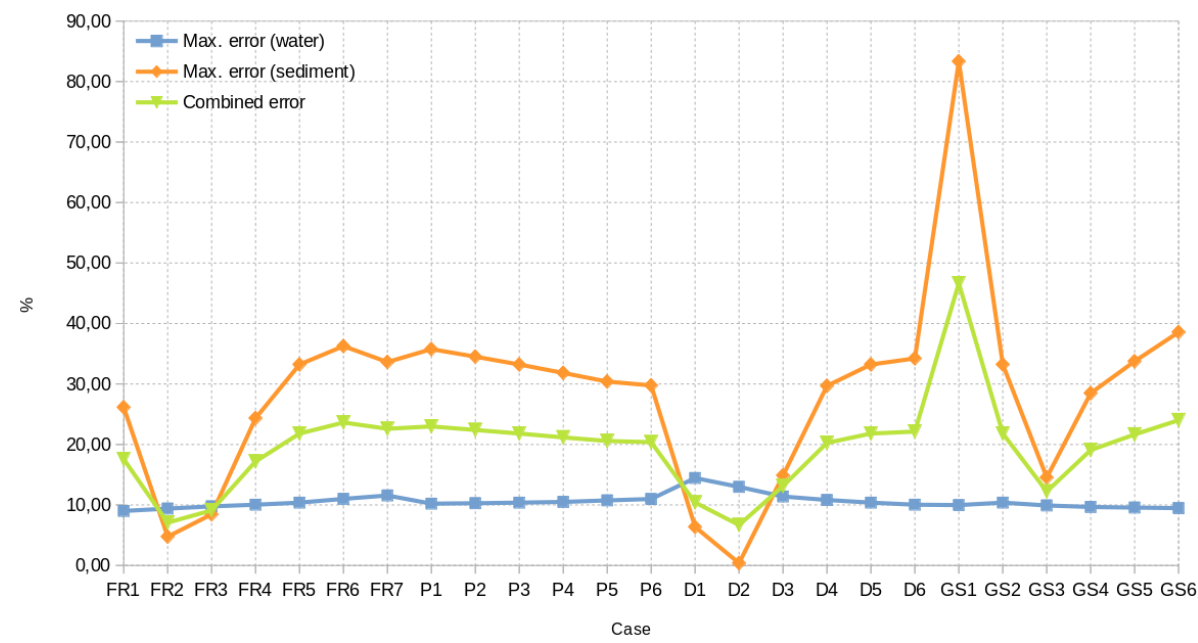

Figure 31: Arnás catchment sediment transport: Relative differences between numerical and observed outlet water and solid volumes. 


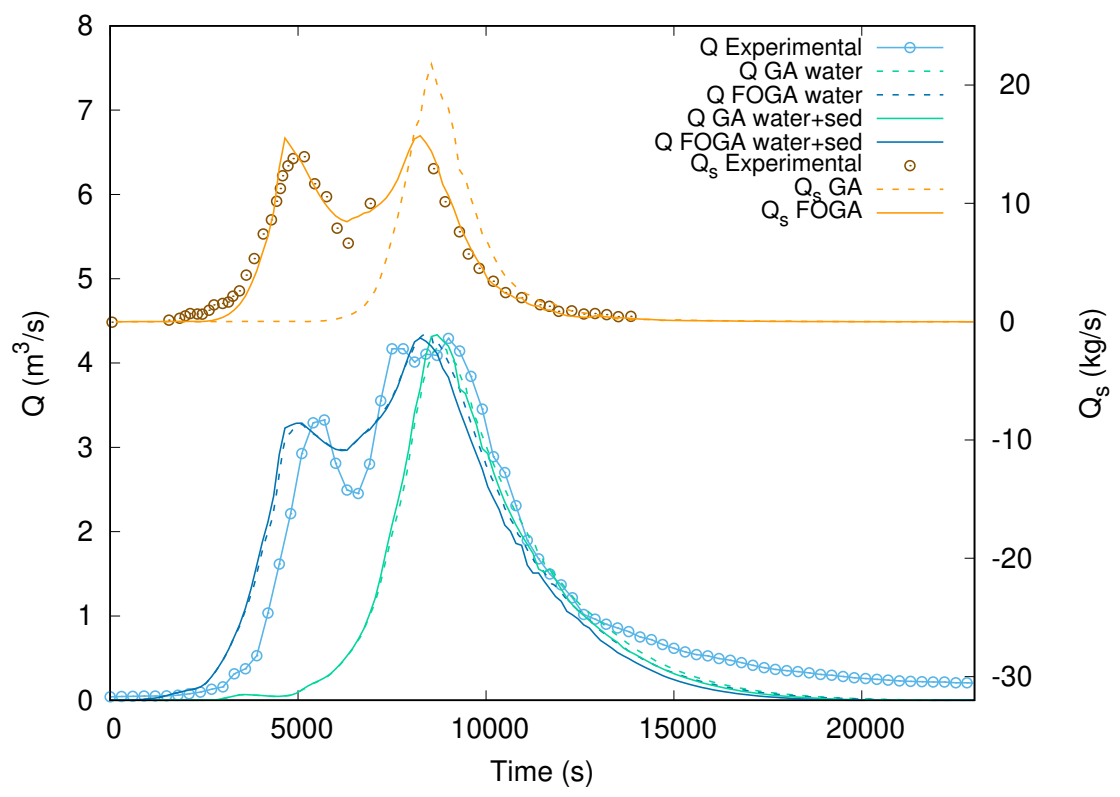

Figure 32: Arnás catchment sediment transport: Best fit for numerical hydrograph and sedigraph provided by the sensitivity analysis.

Figure 33 shows the distributed values for surface water depth at $t=8500 \mathrm{~s}$ (left), cumulative infiltration (center) and changes in bed level (right) at final simulation time $(t=32000 s)$. Figure 34 shows the temporal evolution of the bed level and sediment concentration at two selected gauging points at the catchment outlet (Probe 1) and at the confluence of the two main channels (Probe 2). 


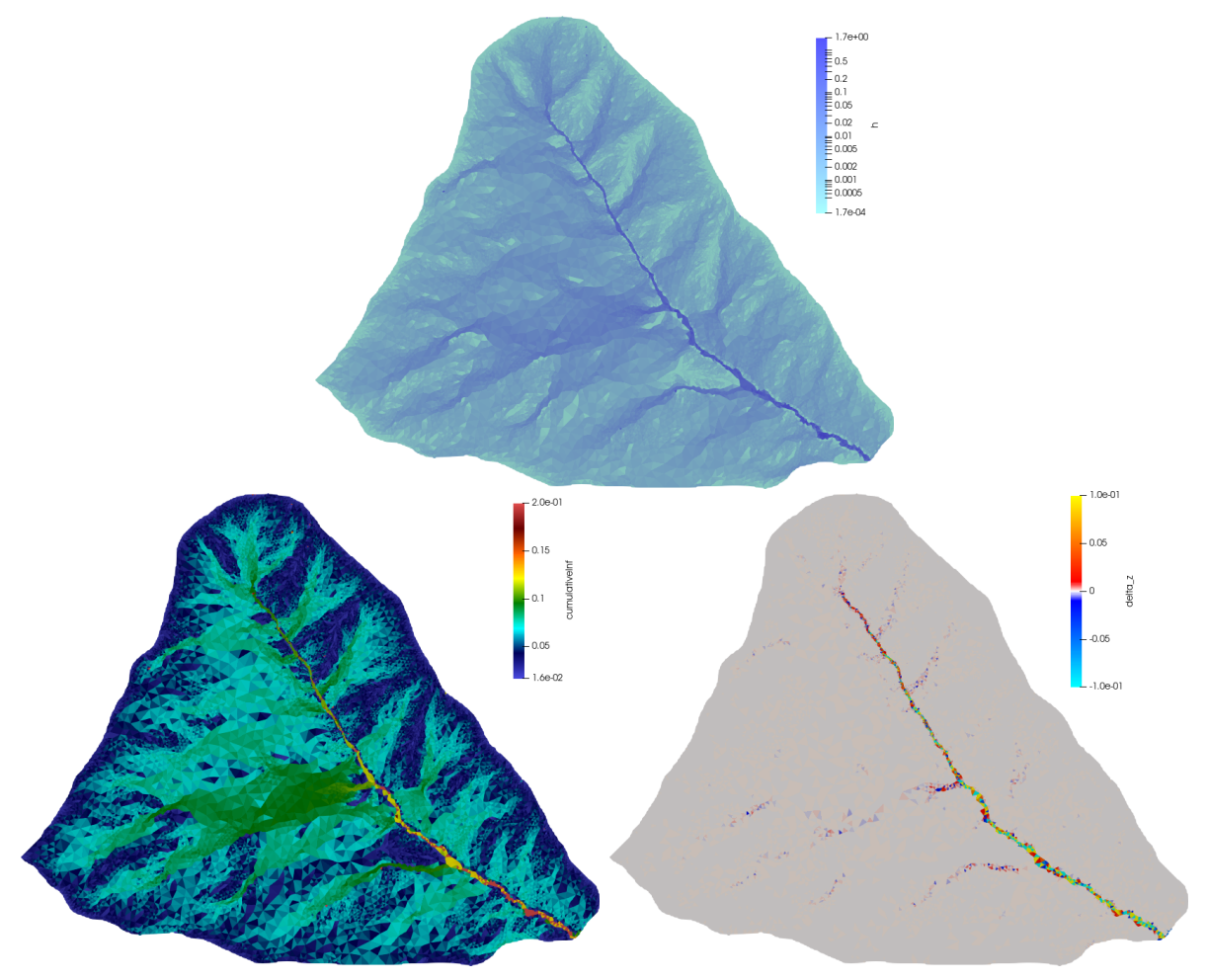

Figure 33: Distributed values for surface water depth at $t=8500 \mathrm{~s}$ (left), cumulative infiltration (center) and changes in bed level (right) at final simulation time $(t=32000 s)$.
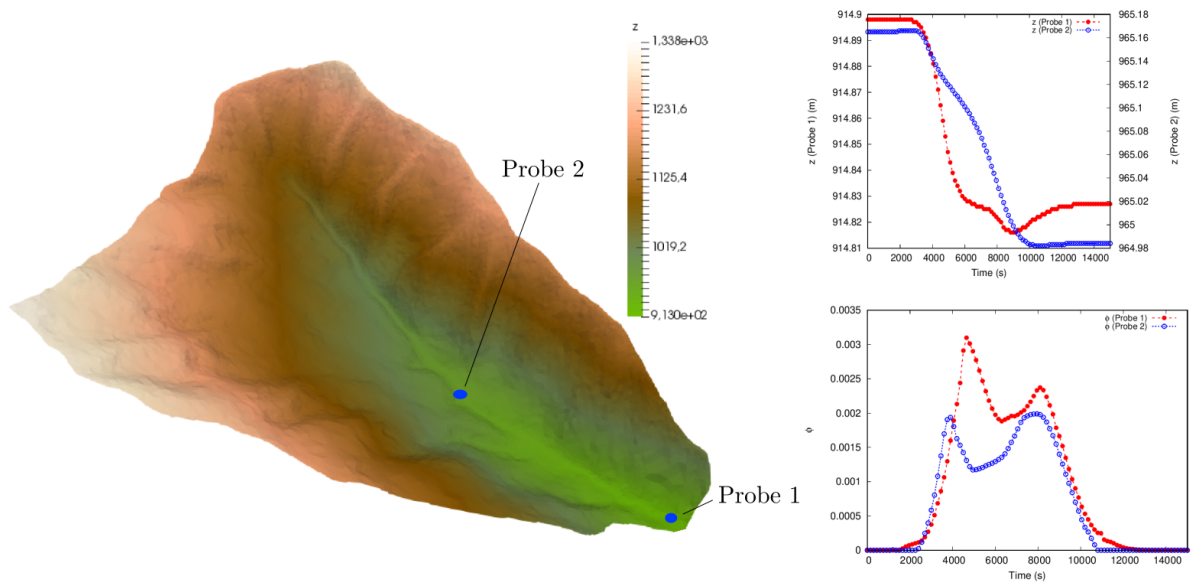

Figure 34: Temporal evolution of the bed level and sediment concentration at two selected gauging points. 


\subsection{Araguás catchment: Hydrological and sedimentological response}

discharge measurements were acquired at the outlet of the basin (see Figure 16 left) with a 5 minutes frequency. Rainfall was registered by a rain gauge also with the same frequency. Figure 35 shows the observed hyetograph and the outlet hydrograph for this particular storm event.
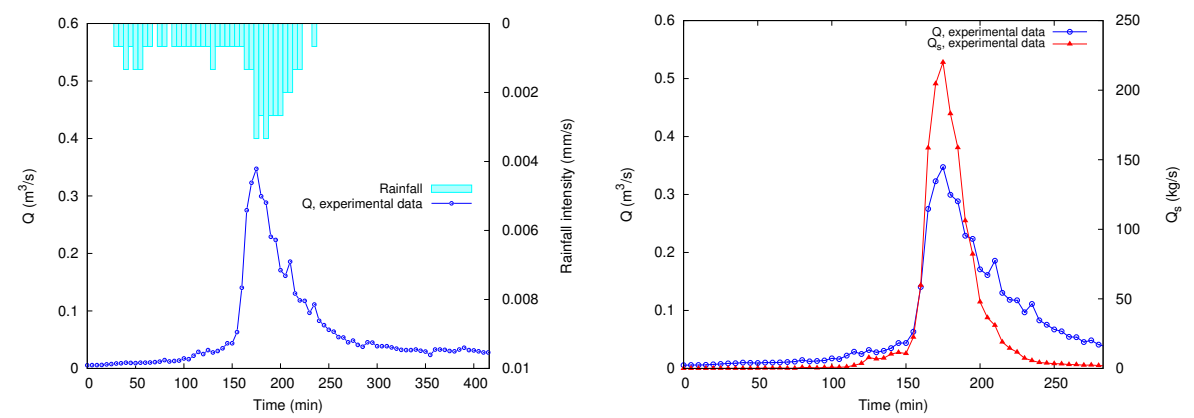

Figure 35: Experimental hyetograph and hydrograph for Araguás basin (left) and the corresponding sedigraph (right).

In the Araguás catchment, the water table evolution has been reporeted not to have relevance 64. Following the guidelines provided by the sensitivity analysis performed in the previous sections, the infiltration and sediment transport model have been calibrated, leading to $K_{\alpha}=9.7 \cdot 10^{-7} \mathrm{~m}^{\alpha} / \mathrm{s}, \Psi=0.02 \mathrm{~m}$, $\Delta \theta=3.0 \mathrm{~m}^{3} / \mathrm{m}^{3}$ for the FOGA model. Regarding the sediment parameters, although Arnás and Araguás catchments are separated only by a few kilometers, the suspended sediment concentration in Araguás is several orders of magnitude larger and the bed load is neglectible in this case [61. A sediment density $\rho_{s}=1800 \mathrm{~kg} / \mathrm{m}^{3}$ is set with a median diameter $d_{50}=7 \cdot 10^{-5} \mathrm{~m}$. Figure 36 shows the outlet hydrograph and sedigraph for the Araguás catchment considering only suspended sediments and the comparison with the observed data. In general, a good numerical response is achieved with a temporal delay in the sediment discharge peak, associated to the hydraulic response. 


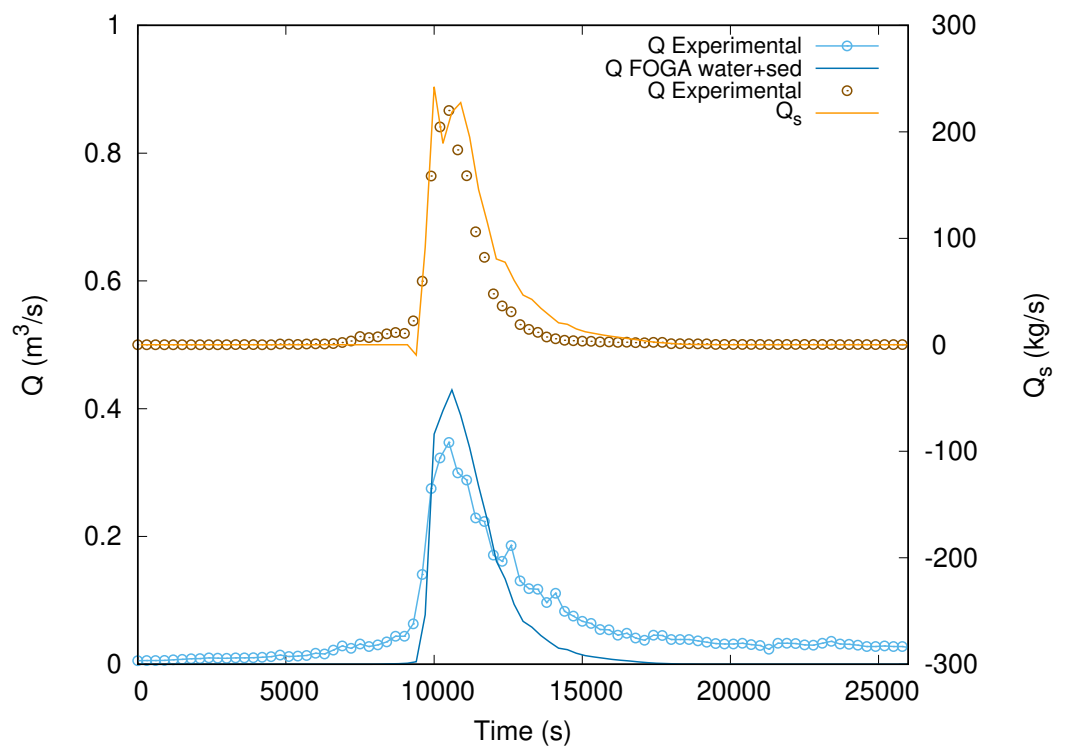

Figure 36: Outlet hydrograph and sedigraph for the Araguás catchment.

Figure 37 shows the distributed values for surface water depth at peak discharge time $(t=10500 s)$ (left), cumulative infiltration (center) and changes ${ }_{645}$ in bed level (right) at final simulation time $(t=30000 s)$. Figure 38 shows the temporal evolution of the bed level and sediment concentration at two selected gauging points at the catchment outlet (Probe 1) and at an intermediate location (Probe 2). 


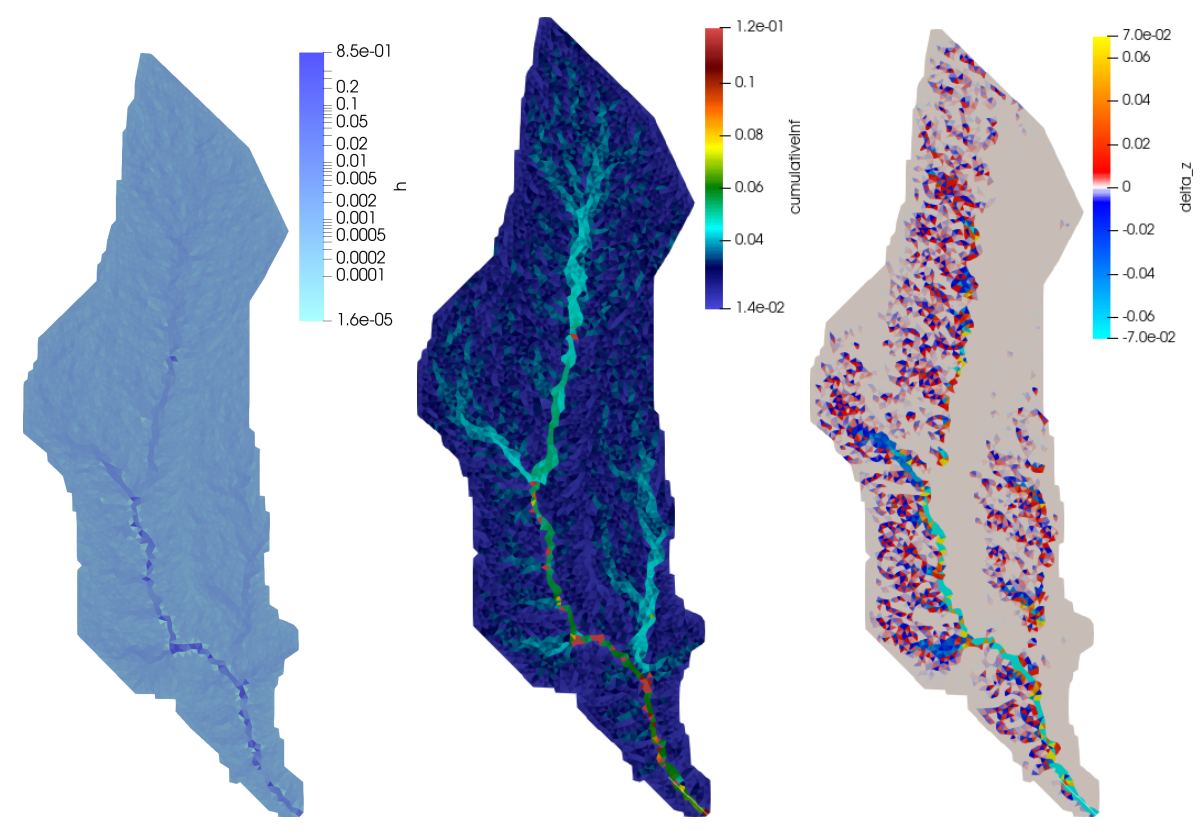

Figure 37: Distributed values for surface water depth at peak discharge time $(t=10500 s)$ (left), cumulative infiltration (center) and changes in bez level (right) at final simulation time $(t=30000 s)$. 

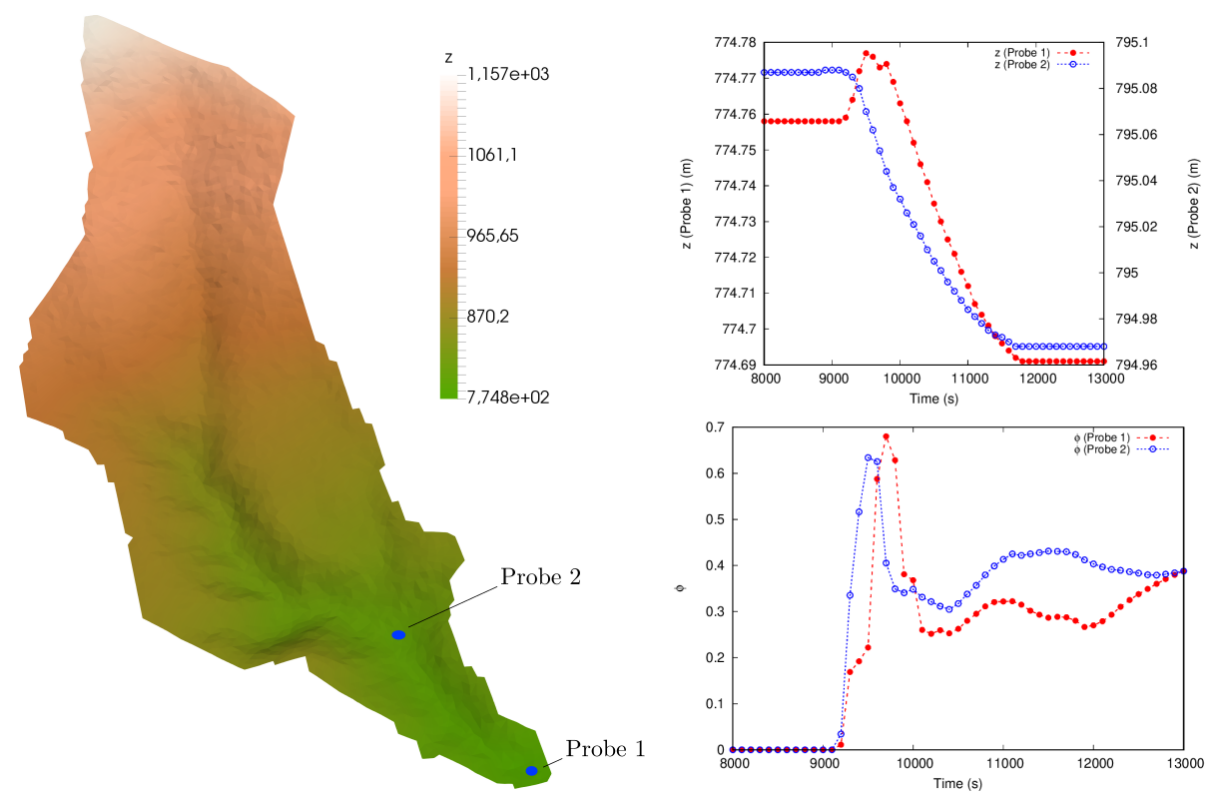

Figure 38: Temporal evolution of the bed level and sediment concentration at two selected gauging points. 


\section{Conclusions}

650 Equations coupled with a fractional-order infiltration law, a sediment transport model and a 2D groundwater flow model for the computation of the phreatic surface evolution. The surface flow model has been numerically solved by an explicit finite volume scheme. The groundwater flow model has been solved by an implicit finite volume model and numerically validated with a test case with analytical solution and a laboratory experiment with measured data. Two field applications have been presented (Arnás and Araguás catchments) in order to provide a hydraulic and sediment model validation. In the case of the Arnás catchment, a study of the influence of the phreatic surface on the outlet hydrograph has been also carried out. In the light of the numerical results, the conclusions of this paper can be summarized in the following points:

- The time step for the coupled model is governed by the surface flow model. It has been shown that the communication frequency between surface and groundwater flows can be reduced up to $25 \mathrm{x}$ without a noticeable quality loss in the numerical results. This leads to an speed-up up to $8 \mathrm{x}$ in the computational cost of the coupled simulation.

- When considering a long storm event (several days), after a short period of adaptation with transient conditions at the soil-surface interface, all the outlet discharge peak are well reproduced in terms of peak values and arrival time. On the contrary, when considering short storm event (few hours), the fit of the numerical discharge to the observed data becomes more complicated. The initial conditions for the soil moisture (usually unknown) and the abrupt changes in soil infiltation capacity curves at early times make necessary the use of a more sophisticated infiltration model (FOGA model) improving significantly both hydrograph and sedigraph

fits.

- The streamflow generation in Arnás catchment can be influenced by the 
phreatic surface evolution. This is specially noticeable in the falling limb of the hydrograph where the exfiltration contributes to improve the match with the observed data. The lack of information regarding the initial water table position hinders the calibrarion process. Nevertheless, the numerical results show the possibility to explain the differences between numerical and observed falling limbs.

- The catchment sedimentary response is straightforwardly dependent on the hydrological calibration of the catchments. Hence, a proper infiltration parameters calibration is mandatory in order to obtain adequate geomorphological catchment simulations. On the other hand, the sensitivity of hydrographs and sedigraph to several parameters has been also studied. Both roughness, density, porosity or sediment grain size directly affect the fit of the numerical curves. For both catchments, it has been found of special relevance to find a correct estimation of the sediment density.

In general terms, 2D distributed models for surface and subsurface flows combined with adequate laws for computing sediment transport and infiltration losses become an excellent tool to provide predictive results at catchment level. The whole basin can be fully discretized and several hydrological/morphodynamical processes can be simulated simulteneously.

As an additional worth to mention concluding remark, the computational cost for all the simulations presented in this paper was less than 5 minutes in a desktop Intel Core i7 processor (paralellized in 6 cores), even for events lasting 8 hours. This leads to the conclusion that these kind of models, despite of its complexity, can be applied nowadays for real-time predictive purposes at catchment level.

\section{Acknowledgments}

The present work was partially funded by the Aragón Government through the Fondo Social Europeo. It has also been supported by the Research Project 
PGC2018-094341-B-I00 funded by the Spanish Ministry of Science, Innovation and Universities (MICINN). The corresponding author also wants to thank the Ministry if Economy and Competitiveness (MINECO) and Hydronia-Europe S.L. for his Research Grant DI-14-06987. The authors would like to thank Dr. Daniel Caviedes-Voullième and Dr. Ignacio García-Palacín for providing the experimental measurings for the validation with laboratory data and Dra. Noemí Lana-Renault and Dra. Estela Nadal-Romero for providing all the Arnás and Araguás catchments measured data. 


\section{References}

715

[1] R. Hershey, R. Fairbridge, Encyclopedia of hydrology and water resources, Kluwer Academic Publishers, 1988.

[2] V. Singh, W. D.A., Mathematical modeling of watershed hydrology, Journal of Hydrologic Engineering 7 (4) (2002) 270-294.

[3] V. Singh, Hydrologic modeling: progress and future directions, Geoscience

[4] D. Liang, I. Özgen, R. Hinkelmann, Y. Xiao, J. Chen, Shallow water simulation of overland flows in idealised catchments, Environmental Earth Sciences 74 (2015) 7307-7318.

[5] J. Fernández-Pato, D. Caviedes-Voullième, P. García-Navarro, Raingroundwater flow model, Journal of Hydrology 142 (1) (1993) $47-69$. doi:https://doi.org/10.1016/0022-1694(93)90004-S, URL http://www.sciencedirect.com/science/article/pii/ $002216949390004 \mathrm{~S}$

[8] B. Witte, R. Hinkelmann, R. Helmig, Development of a parallel fvm based groundwater flow model, in: M. Breuer, F. Durst, C. Zenger (Eds.), High Performance Scientific And Engineering Computing, Springer Berlin Hei- 
[9] T. Broecker, K. Teuber, V. Sobhi Gollo, G. Nützmann, J. Lewandowski,

[12] C. Juez, A. Tena, J. Fernández-Pato, R. Batalla, P. García-Navarro, Application of a distributed 2D overland flow model for rainfall/runoff and $10.3390 /$ w11071517 URL https ://www .mdpi.com/2073-4441/11/7/1517

[10] S. Li, C. Duffy, Fully coupled approach to modeling shallow water flow, sediment transport and bed evolution in rivers, Water Resources Research 47 (3) (2011) W03508.

[11] C. Juez, J. Murillo, P. Garcia-Navarro, Numerical assessment of bedload discharge formulations for transient flow in 1D and 2D situations, JOURNAL OF HYDROINFORMATICS 15 (4) (2013) 1234-1257. doi: $10.2166 /$ hydro.2013.153. erosion simulation in a Mediterranean watershed., Cuadernos de Investigación Geográfica 44 (2) (2018) 615-640.

[13] J. Lewandowski, K. Meinikmann, S. Krause, Groundwater-surface water interactions: Recent advances and interdisciplinary challenges, Water $12(1)$.

[14] M. Hajigholizadeh, A. Melesse, H. Fuentes, Erosion and sediment transport modelling in shallow waters: A review on approaches, models and applications, International Journal of Environmental Research and Public Health 15 (2018) 518.

[15] A. Lacasta, M. Morales-Hernández, J. Murillo, P. García-Navarro, GPU implementation of the $2 \mathrm{D}$ shallow water equations for the simulation of R. Hinkelmann, Integral flow modelling approach for surface watergroundwater interactions along a rippled streambed, Water 11 (7). doi: rainfall/runoff events, Environmental Earth Sciences 74 (11) (2015) 72957305. 
[16] N. Lana-Renault, J. Latron, D. Regüés, Streamflow response and watertable dynamics in a sub-mediterranean research catchment (central pyrenees), Journal of Hydrology 347 (2007) 497-507.

[17] N. Lana-Renault, D. Regüés, Bedload transport under different flow conditions in a human-disturbed catchment in the central spanish pyrenees, Catena 71 (2007) 155-163.

[18] D. López-Barrera, P. García-Navarro, P. Brufau, Sources of uncertainty in the validation of a coupled hydrological-hydraulic simulation model with sediment transport, La Houille Blanche 3 (2011) 17-22.

[19] D. Caviedes-Voullième, P. García-Navarro, J. Murillo, Influence of mesh structure on 2D full shallow water equations and SCS Curve Number simulation of rainfall/runoff events, Journal of Hydrology 448-449 (0) (2012) $39-59$.

[20] D. Caviedes-Voulliéme, J. Fernández-Pato, C. Hinz, Performance assessment of $2 \mathrm{~d}$ zero-inertia and shallow water models for simulating rainfallrunoff processes, Journal of Hydrology 584 (2020) 124663.

[21] A. Lacasta, M. Morales-Hernández, J. Murillo, P. García-Navarro, An optimized GPU implementation of a 2D free surface simulation model on unstructured meshes, Advances in Engineering Software 78 (2014) 1-15.

[22] J. Fernández-Pato, M. Morales-Hernández, P. García-Navarro, Implicit finite volume simulation of $2 \mathrm{D}$ shallow water flows in flexible meshes, Computer Methods in Applied Mechanics and Engineering 328 (2018) 1 - 25.

[23] V. Voller, On a fractional derivative form of the green-ampt infiltration model, Advances in Water Resources 34 (2) (2011) 257 - 262.

[24] D. Benson, M. Meerschaert, J. Revielle, Fractional calculus in hydrologic modeling: A numerical perspective, Advances in Water Resources 51 (2013) 479 - 497, 35th Year Anniversary Issue. 
[25] W. Lowdermilk, Forests and streamflow: a discussion of hoyt-trozell report, Journal of Forestry 21 (1934) $296-307$.

[26] C. Hursh, Storm water and absorption, Trans Am Geophys Union 17 (II) (1936) $301-302$.

[27] C. Hursh, E. Brater, Separating hydrographs into surface- and subsurface-

[28] I. Remson, J. Randolph, H. Barksdale, The zone of aeration and ground water recharge in sandy sediments at seabrook, new jersey, Soil Science 89 (3) (1960) $145-156$.

[29] J. Hewlett, Soil moisture as a source of base flow from steep mountain watersheds, Southeast Forest Experiment Station Paper 132, USDA Forest Service (1961).

[30] J. Hewlett, Some ideas about storm runoff and base flow, Southeast forest experiment station annual report, USDA Forest Service (1961).

[31] W. Wu, Computational River Dynamics, NetLibrary, Inc., CRC Press, 2007.

[32] Z. Cao, Y. Li, Z. Yue, Multiple time scales of alluvial rivers carrying suspended sediment and their implications for mathematical modeling, Advances in Water Resources 30 (4) (2007) 715-729.

[33] C. Vreugdenhil, Numerical Methods for Shallow Water Flow, Kluwer Academic Publishers, Dordrecht, The Netherlands, 1994.

[34] J. Murillo, P. García-Navarro, Weak solutions for partial differential equations with source terms: Application to the shallow water equations, Journal of Computational Physics 229 (2010) 4327-4368.

[35] J. Murillo, P. García-Navarro, An exner-based coupled model for twodimensional transient flow over erodible bed, Journal of Computational Physics 229 (23) (2010) 8704-8732. 
[36] C. Juez, J. Murillo, P. García-Navarro, A 2D weakly-coupled and efficient numerical model for transient shallow flow and movable bed, Advances in Water Resources 71 (0) (2014) 93 - 109.

[37] U. S. D. of Agriculture (USDA), Urban hydrology for small watersheds, Environment agency report, United States Department of Agriculture (USDA) (1986).

[38] S. Mishra, V. Singh, Soil Conservation Service Curve Number (SCS-CN) Methodology, Kluwer Academic Publishers, 2003.

[39] V. Te Chow, D. Maidment, L. Mays, Applied Hydrology, McGraw-Hill Civil Engineering Series, MCGRAW-HILL Higher Education, 1988.

[40] W. Green, G. Ampt, Studies on soil physics: 1. flow of air and water through soils, Journal of Agricultural Science 4 (1911) 1-24.

[41] R. G. Mein, C. L. Larson, Modeling infiltration during a steady rain, Water Resources Research 9 (2) (1973) 384-394.

[42] K. Diethelm, The analysis of fractional differential equations, Vol. 2004 of Lecture Notes in Mathematics, Springer-Verlag, Berlin, 2010, an application-oriented exposition using differential operators of Caputo type.

[43] G. Smart, Sediment transport formula for steep channels, Journal of Hydraulic Engineering 3 (1984) 267-276.

[44] C. Juez, A. Lacasta, J. Murillo, P. García-Navarro, An efficient GPU implementation for a faster simulation of unsteady bed-load transport, Journal of Hydraulic Research 54 (3) (2016) 275-288.

[45] R. Zhang, River Dynamics (in Chinese), Industry Press, 1961.

845 [46] L. van Rijn, Sediment transport, part ii: suspended load transport, Journal of Hydrulic Engineering 11 (110) (1984) 1613 - 1641. 
[47] H. Darcy, Les fontaines publiques de la ville de dijon, Tech. rep., Dalmont, Paris (1957).

[48] H. van der Vorst, BI-CGSTAB - A fast and smoothly converging variant of BI-CG for the solution of nonsymmetric linear-systems, SIAM Journal on Scientific and Statistical Computing 13 (2) (1992) 631-644.

[49] G. Guennebaud, B. Jacob, et al., Eigen v3, http://eigen.tuxfamily.org (2010).

[50] Y. Saad, ILUT: A dual threshold incomplete LU factorization, Numerical Linear Algebra with Applications 1 (4) (1994) 387-402.

[51] J. Fernández-Pato, P. García-Navarro, 2D zero-inertia model for solution of overland flow problems in flexible meshes, Journal of Hydrologic Engineering 21 (11) (2016) 04016038.

[52] J. Fernández-Pato, P. García-Navarro, Numerical simulation of valley flood using an implicit diffusion wave model, Ingeniería del agua 20 (3) (2016) $115-126$.

[53] D. Caviedes-Voullième, A computational model for the simulation of multidimensional hydrodynamics and transport at the soil-surface interface, Ph.D. thesis, EINA - Universidad de Zaragoza (2013).

[54] M. Seeger, M.-P. Errea, S. Beguería, J. Arnáez, J. Martí, C. García-Ruíz, Catchment soil moisture and rainfall characteristics as determinant factors for discharge/suspended sediment hysteretic loops in a small headwater catchment in the spanish pyrenees, Journal of Hydrology 288 (2004) 299311.

[55] A. Navas, J. Machín, S. Beguería, López-Vicente, M., L. Gaspar, Soil properties and physiographic factors controlling the natural vegetation regrowth in a disturbed catchment of the central spanish pyrenees, Agroforestry Systems 72 (3) (2008) 173-185. 
[56] L. Alatorre, S. Beguería, N. Lana-Renault, A. Navas, J. García-Ruíz, Soil erosion and sediment delivery in a mountain catchment under scenarios of land use change using a spatially distributed numerical model, Hydrology and Earth System Sciences 16 (2012) 1321-1334.

[57] N. Lana-Renault, J. Latron, D. Karssenberg, D.and Regüés, M. Bierkens, Differences in stream flow in relation to changes in land cover: A comparative study in two sub-mediterranean mountain catchments, Journal of Hydrology 411 (2011) 366-378.

[58] E. Nadal-Romero, J. Latron, C. Martí-Bono, D. Regüés, Temporal distribution of suspended sediment transport in a humid mediterranean badland area: The araguás catchment, central pyrenees, Geomorphology 97 (2008) 601-616.

[59] C. Duvert, G. Nord, N. Gratiot, O. Navratil, E. Nadal-Romero, N. Mathys, J. Némery, D. Regüés, J. García-Ruiz, F. Gallart, M. Esteves, Towards prediction of suspended sediment yield from peak discharge in small erodible mountainous catchments $(0.45-22 \mathrm{~km} 2)$ of france, mexico and spain, Journal of Hydrology 454-455 (2012) 42-55.

[60] D. Regüés, E. Nadal-Romero, Uncertainty in the evaluation of sediment yield from badland areas: Suspended sediment transport estimated in the araguás catchment (central spanish pyrenees), Catena 106 (2013) 93-100.

[61] J. García-Ruiz, D. Regüés, B. Alvera, N. Lana-Renault, P. Serrano-Muela, E. Nadal-Romero, A. Navas, J. Latron, C. Martí-Bono, J. Arnáez, Flood generation and sediment transport in experimental catchments affected by land use changes in the central pyrenees, Journal of Hydrology 356 (2008) $245-260$.

[62] J. García-Ruiz, N. Lana-Renault, S. Beguería, T. Lasanta, D. Regüés, E. Nadal-Romero, P. Serrano-Muela, J. López-Moreno, B. Alvera, C. MartíBono, L. Alatorre, From plot to regional scales: Interactions of slope and 
catchment hydrological and geomorphic processes in the spanish pyrenees, Geomorphology 120 (3-4) (2010) $248-257$.

[63] E. Nadal-Romero, D. Regüés, C. Martí-Bono, P. Serrano-Muela, Badland dynamics in the central pyrenees: temporal and spatial patterns of weathering processes, Earth Surface Processes and Landforms 32 (6) (2007) 888904.

[64] E. Nadal-Romero, D. Regüés, J. Latron, Relationships among rainfall, runoff, and suspended sediment in a small catchment with badlands, Catena 74 (2008) 127-136. 